\title{
Dark aeolian sediments in Martian craters: Composition and sources
}

\author{
D. Tirsch, ${ }^{1}$ R. Jaumann, ${ }^{1,2}$ A. Pacifici, ${ }^{3}$ and F. Poulet ${ }^{4}$ \\ Received 18 December 2009; revised 26 July 2010; accepted 30 November 2010; published 3 March 2011.
}

[1] Our research focuses on the mineralogical characteristics of dark sediment deposits in Martian craters (dunes, dune fields, and sand sheets) and their local sediment sources, carried out on the basis of 70 selected localities. Morphological analyses reveal dark layers exposed in a number of crater walls, showing indications of material transport from the layers downwall to the intracrater deposits. Additional sites show dark sediment emerging from several craters floors, suggesting a dark material source beneath the crater floor. Spectral analyses of OMEGA and CRISM data showed for the first time that a direct mineralogical connection exists between the dark layers in the crater walls and the intracrater dune and sand sheet material. Based on these findings, it is shown that these layers are the local sources for the dark aeolian sediment inside the craters. Spectral analyses further indicate that all deposits are nearly of the same mafic mineralogical composition, hinting at a similar origin. We conclude that the mineralogical composition points to a volcanic origin of the material. The dark layers which we infer to be the material sources might represent layers of volcanic ash, almost globally deposited in Early Noachian times and subsequently covered by regolith. Groundwater, impact erosion, and crustal movement led to the highly fragmented situation of the dark layers today.

However, burial protected the layers of dark sediment from chemical alteration caused by surficial fluvial processes. Impact erosion after the wet periods on Mars led to the exposure and mobilization of the material today.

Citation: Tirsch, D., R. Jaumann, A. Pacifici, and F. Poulet (2011), Dark aeolian sediments in Martian craters: Composition and sources, J. Geophys. Res., 116, E03002, doi:10.1029/2009JE003562.

\section{Introduction}

[2] Dark features on Mars were first discovered by Mariner 6 and 7 [Christensen, 1983]. Mariner 9 and the Viking orbiters revealed that these dark features are frequently associated with impact craters at all latitudes and in a variety of terrains [McCauley et al., 1972; Sagan et al., 1972; Arvidson, 1974]. Before it was ascertained that the intracrater features are sand dunes mostly coupled with wind streaks, dark "splotches" was the term most commonly used to designate these deposits [e.g., Christensen, 1983; Thomas, 1984]. The fine-grained dark aeolian sediment is not only concentrated in impact craters, but also covers extensive regions on Mars. Many authors thought the dark areas were exclusively due to the absence of bright dust and covered by saltating sand, which keeps the surface clean of bright dust [e.g., Sagan et al., 1972; Christensen, 1983; Thomas, 1984; Edgett and Christensen, 1994]. According to Edgett and

\footnotetext{
${ }^{1}$ Institute of Planetary Research, German Aerospace Center, Berlin, Germany.

${ }^{2}$ Department of Geological Sciences, Free University, Berlin, Germany.

${ }^{3}$ IRSPS, Universita d'Annunzio, Pescara, Italy.

${ }^{4}$ Institut d'Astrophysique Spatiale, Université Paris-Sud, Orsay, France.

Copyright 2011 by the American Geophysical Union. 0148-0227/11/2009JE003562
}

Malin [2000], next to bright dust and dark sand, bright saltating sands and dark fines can also be found. However, transported by suspension in the atmosphere, dark fines are unable to build aeolian bed forms but cover extensive regions on Mars [Edgett and Malin, 2000].

[3] Early studies described the distribution, color, and morphology as well as the physical properties of the dark sediment, arriving at a particle size range for which aeolian transport is suggested [e.g., Breed, 1977; Breed et al., 1979; Christensen, 1983; Thomas, 1984; Edgett and Blumberg, 1994]. Further investigations determined the effective particle size of the dark Martian dunes to be in the medium to coarse-grained range, revealing that Martian dunes seem to be coarser grained than typical terrestrial dunes [Edgett and Christensen, 1991, 1994]. Early spectral analyses of the dark sediment as performed by Singer and McCord [1979] and Singer [1980a, 1980b] revealed a basaltic composition of pyroxenes and olivines disclosing the unaltered nature of the sediments. These spectroscopic analyses have been continued and refined by various authors [e.g., Christensen et al., 2000; Bibring and Erard, 2001; Christensen et al., 2001; Bandfield, 2002; Christensen et al., 2003; Bonello et al., 2004; Bibring et al., 2005; Mangold et al., 2007; Mustard et al., 2007; Poulet et al., 2007, 2008; Christensen et al., 2004], who similarly concluded that the material 


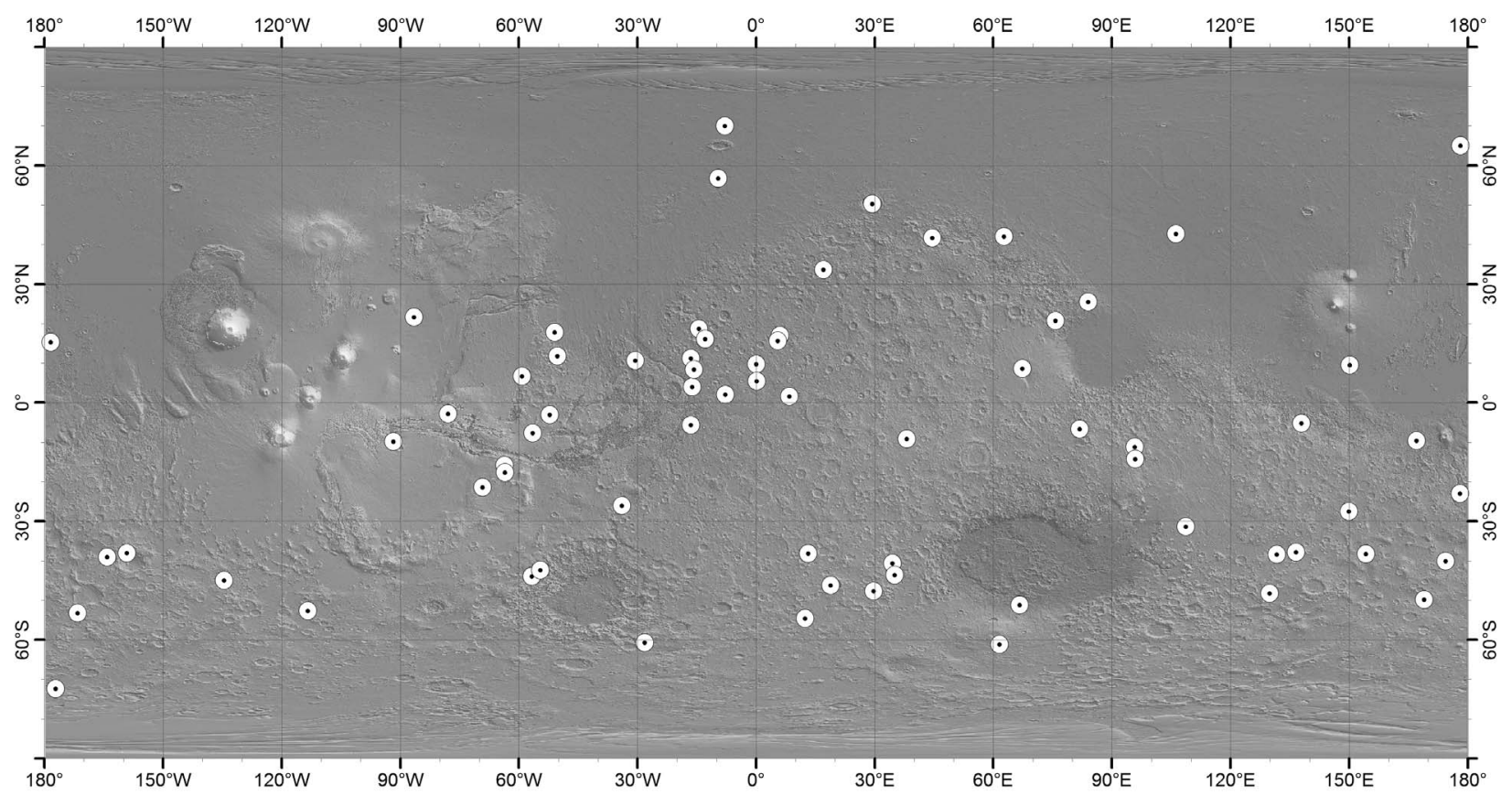

Figure 1. Global locations of the 70 deposits investigated (background is MOLA topography map).

composition is mafic. Most of the analyses of dark dunes concentrate on distinct dune fields or regions on Mars, by studying its local morphology, physical properties, and aeolian processes and reveal a variety of dune shapes, the existence of possibly active and nonactive dunes, and the complexity of dune-forming winds [e.g., Greeley et al., 1992, 1993, 1999; Fenton and Bandfield, 2003; Bourke, 2005; Fenton, 2005a, 2005b, 2006; Fenton and Mellon, 2006]. Thus, there is still a need for a comparative and global view on the overall composition of these deposits. Furthermore, the source of the dark sediment is still unsolved. Edgett [2002] observed correlations between dark dunes associated with exposures of eroded layered material in several craters at Arabia Terra. He suggested that these layers might contribute a portion of the dark sediments. However, he realized that the light-toned color of the layers contrasted with the dark tone of the dune and wind streak sediments. Although some darker layers are present at some of these locations, he found that the difference in color between the layers and the dunes rules out a generic connection between the eroded layers and the dark sediment. Fenton [2005a, 2008] found tentative indications of potential dark sand sources in dark layers exposed in the pit walls of a big crater at Noachis Terra. Although a number of previous studies were concerned with dark dunes and dark sediment as such, the scenario of the origin and evolution of these dark sediments is not understood yet.

\section{Data Sets}

[4] The High Resolution Stereo Camera (HRSC) on Mars Express [Jaumann et al., 2007; Neukum et al., 2004a] is a multisensor push broom instrument, which delivers images of the Martian surface and atmosphere at various spatial resolutions. HRSC nadir image data build the basis for this analysis. Because of the spatial resolution of $12.5 \mathrm{~m} \mathrm{HRSC}$ image data provide excellent overview images showing the entire dark sediment craters with a satisfactory resolution of ground details. The use of radiometrically and geometrically calibrated data [Scholten et al., 2005; Jaumann et al., 2007] made further systematic processing unnecessary except for the creation of subsets for every location and mosaics in places where huge craters could not be covered by one HRSC orbit alone. Additionally, HRSC digital terrain models (DTMs) with a spatial resolution of 50-75 m (vertical accuracy $=90 \%$ of the nadir resolution [ Gwinner et al., $2005,2009 a, 2009 b]$ ) were used to measure the morphometric parameters of the craters and dunes.

[5] Where available, Mars Orbiter Camera (MOC) data [Malin et al., 1992] are used to gain a higher- resolution view on the objects of investigation. The MOC images used in this study are narrow-angle images with a spatial resolution of $2.8 \mathrm{~m} /$ pixel. The data were downloaded from the Malin Space Science Systems web page (www.msss.com/mgs/ moc/index.html), transformed into VICAR (Video Image Communication And Retrieval) format, and map projected in order to fit onto the HRSC data sets. Images were visually interpreted to recover detail information such as dune types and exposed dark layers in crater walls.

[6] The mineralogical composition of the dark sediment was examined with the aid of near-infrared spectral reflectance data from the visual infrared mapping spectrometer OMEGA (Observatoire pour la Minéralogie, l'Eau, les Glaces, et l'Activité) [Bibring et al., 2004]. The used spectral range of $1-2.5 \mu \mathrm{m}$ exhibits most mineral diagnostic absorption bands. The radiance data were corrected for atmospheric absorption and solar irradiance using standard reduction schemes described by Bellucci et al. [2006] and Bibring et al. [2006]. Atmospheric correction of the spectral data is necessary because observations of surface reflectance also include atmospheric contributions from dust, water vapor, water-ice aerosols, and $\mathrm{CO}_{2}$ [Mustard et al., 2005]. 

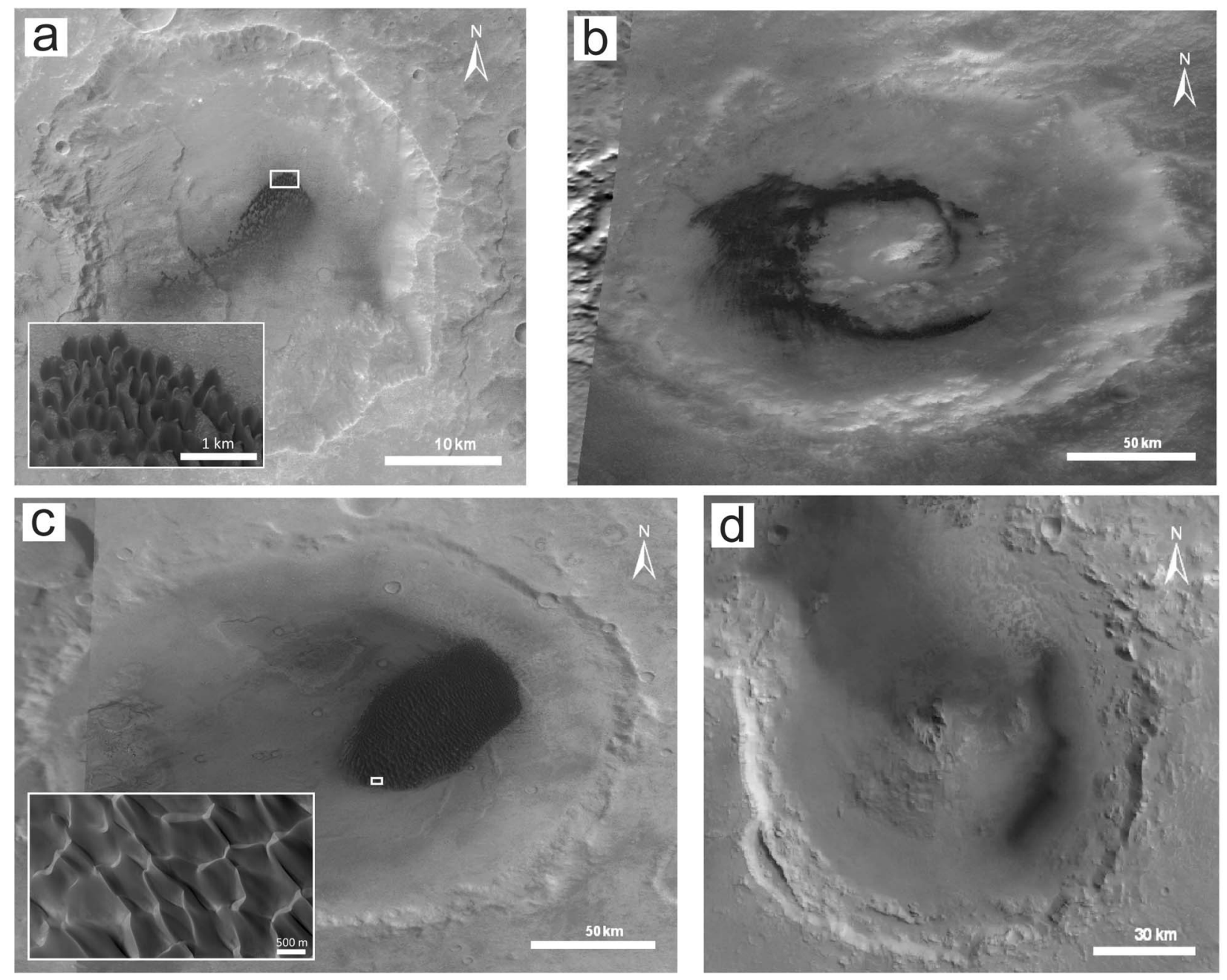

Figure 2. Different types of dark aeolian sediment deposits in Martian craters. (a) Barchan dune field in a crater in Tyrrhena Terra $\left(14.3^{\circ} \mathrm{S}, 95.8^{\circ} \mathrm{E}\right.$; HRSC 0038 0000). White box indicates position of the zoom image (MOC S1201979). (b) Circular dune field in Liu Hsin crater associated with a sand sheet $\left(53.5^{\circ} \mathrm{S}\right.$, $188.4^{\circ} \mathrm{E}$; HRSC mosaic of 4381_0009, 4370_0000, and 4359_0000). (c) Complex dune field in Proctor crater $\left(47.9^{\circ} \mathrm{S}, 29.5^{\circ} \mathrm{E}\right.$; HRSC mosaic of $2529 \_0000$ and $\left.2496-0000\right)$. White box indicates position of the zoom image (HiRISE red channel of PSP_002824_1355). ( $\bar{d})$ Sand sheet in Oudemans crater $\left(9.8^{\circ} \mathrm{S}\right.$, 268.2 ${ }^{\circ} \mathrm{E}$; HRSC 0442_0008).

The data correction procedure generates reflectance $\mathrm{I} / \mathrm{F}$ (ratio of observed radiance to incoming solar flux per surface unit [Poulet et al., 2007]) spectra, which reliably reflect the intrinsic properties of the surface. Prior to the atmospheric correction, all OMEGA data sets were geometrically corrected. The OMEGA data used for this study have different spatial resolutions, which range from $300 \mathrm{~m}$ to $3 \mathrm{~km}$, depending on the size of the respective dune field or sand sheet as well as on data availability. The data sets used as a crater database in this study are listed the auxiliary material. ${ }^{1}$

[7] Further data from orbital Martian missions were only used for selected places. Mars Orbiter Laser Altimeter (MOLA) data were used as a base map in the GIS, providing

\footnotetext{
${ }^{1}$ Auxiliary materials are available in the HTML. doi:10.1029/ 2009JE003562.
}

a global shaded relief with elevation information. This MOLA base map forms the background of every global image shown in this work. For certain locations, MOLA elevation information (vertical precision $<10 \mathrm{~m}$ [Zuber et al., 1998]) is also used when HRSC data provided insufficiently accurate values due to the lack of high-resolution HRSC DTMs. Additionally, data from the High Resolution Imaging Science Experiment (HiRISE) and the Compact Reconnaissance Imaging Spectrometer for Mars (CRISM), respectively, provide high-resolution image and spectral data of extraordinarily high quality and spatial resolution. Detailed instrument descriptions are given by McEwen et al. [2007] for HiRISE and Murchie et al. [2004], Silverglate et al. [2004], and Silverglate and Fort [2004] for CRISM. These image and spectral data sets are so far only acquired for a few localities. HiRISE images with a spatial resolution of $25 \mathrm{~cm} /$ pixel 
Table 1. Spectral Parameters Used for Mineral Detection With Corresponding Detection Thresholds Adapted From Poulet et al. [2007]

\begin{tabular}{|c|c|c|c|}
\hline Name & Formulation & Detection Threshold & Rationale \\
\hline NIR albedo & $\frac{R(1.08)}{\cos (i)}$ & N/A & lambertian albedo \\
\hline $0.55 \mu \mathrm{m}$ band depth or $\mathrm{Fe}^{3+}$ parameter & $\frac{1-R(0.55)}{0.5(R(0.44)+R(0.65))}$ & 0.00 & $\begin{array}{l}\text { degree of oxidation or amount of dus } \\
\text { contamination of the surface }\end{array}$ \\
\hline Nanophase ferric oxide or $1 / 0.8 \mu \mathrm{m}$ slope & $\frac{R(0.97)}{R(0.80)}$ & 1.00 & nanophase ferric oxides if ratio $\leq 1$ \\
\hline Pyroxene & $\frac{1-(R(2.15)+R(3.33))}{R(1.81)+R(2.49)}$ & 0.01 & $\begin{array}{l}2 \mu \mathrm{m} \text { band due to both low-calcium } \\
\text { and high-calcium pyroxenes }\end{array}$ \\
\hline Forsterite or Mg-rich olivine & $\frac{0.5(R(1.54)+R(1.56))}{0.1 \cdot R(1.01)+0.2 \cdot R(1.21)+0.7 \cdot R(1.36)}$ & 1.04 & $1 \mu \mathrm{m}$ band due to $\mathrm{Mg}$-rich olivine \\
\hline Fayalite or Fe-rich olivine & $\frac{0.5(R(1.69)+R(1.70))}{0.1(R(1.01)+R(1.21))+0.4(R(1.36)+R(1.50))}$ & 1.02 & $\begin{array}{l}1 \mu \mathrm{m} \text { band due to Fe-rich olivine } \\
\text { and/or large grain size }(>1 \mathrm{~mm})\end{array}$ \\
\hline $\begin{array}{l}1.9 \mu \mathrm{m} \text { band depth or hydrated } \\
\text { mineral }\end{array}$ & $1-\frac{R(1.93)+R(1.94)}{R(1.83)+R(2.12)}$ & 0.02 & water-bearing mineral \\
\hline Water ice & $1-\frac{R(1.50)+R(1.51)}{R(1.30)+R(1.71)}$ & 0.00 & $1.5 \mu \mathrm{m}$ band due to water ice \\
\hline $\mathrm{CO}_{2}$ ice & $1-\frac{R(1.43)}{0.5 \cdot R(1.38)+0.5 \cdot R(1.44)}$ & 0.00 & $1.43 \mu \mathrm{m}$ band due to $\mathrm{CO}_{2}$ ice \\
\hline
\end{tabular}

provide an impressive insight into the details of dark layers in crater walls and dune morphology. Thanks to CRISM's spatial resolution ranging from 15 to $19 \mathrm{~m}$ and the spectral range of $0.37-3.92 \mu \mathrm{m}$, it was possible to derive spectral information on the mineralogical composition of these layers [Pelkey et al., 2007].

\section{Selection of Investigation Areas}

[8] Our analysis of dark material focuses on the dark sediments deposits inside Martian impact craters. Although dark material can be found outside of craters as well, these kind of depressions are the primary accumulation site for dark sediment [e.g., Fenton et al., 2007; Fenton and Hayward, 2008; Hayward et al., 2007a, 2007b; Greeley et al., 1992; Mullins et al., 2005]. A further advantage of craters as investigation sites is that they are globally distributed and thus support a global analysis. The choice of impact craters is mainly driven by geographical location and the accumulation type of the sediment, which should cover the variety of appearances (see below). Image quality was a factor limiting the selection of craters at higher latitudes. These images are often affected by atmospheric dust. Thus they were neither usable for any visual analysis nor was it possible to derive reliable digital terrain information. However, terrain information is needed to derive crater profiles and to measure morphometric parameters. The selected craters are located between the latitudes of $70^{\circ} \mathrm{N}$ and $70^{\circ} \mathrm{S}$. Not all localities are impact craters. Exceptions include one probable collapse depression in Ophir Planum (called "Ophir 1" in this study, $2.9^{\circ} \mathrm{S}, 307.8^{\circ} \mathrm{E}$, north of Valles Marineris) and the dune field in the caldera of the Nili Patera volcano $\left(8.8^{\circ} \mathrm{S}, 67.3^{\circ} \mathrm{E}\right.$, Syrtis Major). The global distribution of all localities is shown in Figure 1. The exact geographical locations of these investigation areas are listed in the auxiliary material.

[9] The selected localities feature the whole range of morphological appearances of dark aeolian sediments such as clusters of single dunes, huge dune fields, and thin sand sheets. In some places, a mixture of these morphological appearances (e.g., dune fields associated with sand sheets) can be observed. Dark dunes obviously exhibit a great variety of shapes. Moreover, the craters where dark material occurs also differ greatly in type. They include large, degraded craters, craters with central peaks, very young and fresh craters, as well as craters with ejecta blankets (rampart and pedestal craters). The general appearance of dark aeolian sediments in Martian craters can be divided into four categories: small clusters of single dunes, dunes associated with sand sheets aligned around obstacles such as central peaks, spacious huge compound or complex dune fields, and thin sand sheets. Examples of these categories are shown in Figure 2.

\section{Methods}

\subsection{Mineral Detection}

[10] The theory behind the determination of minerals or mineral mixtures by spectral analysis are crystal lattice vibrations in minerals caused by material-photon interactions modifying the spectral signal from surfaces in distinct ways [e.g., Adams, 1975; Bonello et al., 2004; Burns, 1970; McCord and Clark, 1978; Mustard, 2002; Pieters, 1977]. In the ultraviolet, visible, or infrared wavelength, minerals have diagnostic absorptions [Adams, 1975; Bell et al., 1975; Lucey and Clark, 1984]. Our mineral detection follows the spectral feature analysis technique as described in detail by Poulet et al. [2007] and was applied to geometrically and atmospherically corrected OMEGA data. The spectral parameters (also referred herein to as spectral indices or spectral criteria) used for mineral identification were also obtained from Poulet et al. [2007] and are listed in Table 1. Detection thresholds for each mineral absorption are defined by Poulet et al. [2007] to keep the signal level significantly above instrumental noise and atmospheric artefacts.

[11] Based on former studies, it is assured that the regions on Mars which are covered by dark sediments are dominated by mafic volcanic rock minerals such as pyroxene and olivine [e.g., Christensen et al., 2000; Bandfield, 2002; Bibring and Erard, 2001; Bibring et al., 2006; Hoefen et al., 2003; Mangold et al., 2007; Mustard et al., 2005, 2007] as well as plagioclase [Christensen et al., 2000]. Therefore, a mafic composition of the dark material was assumed, and 

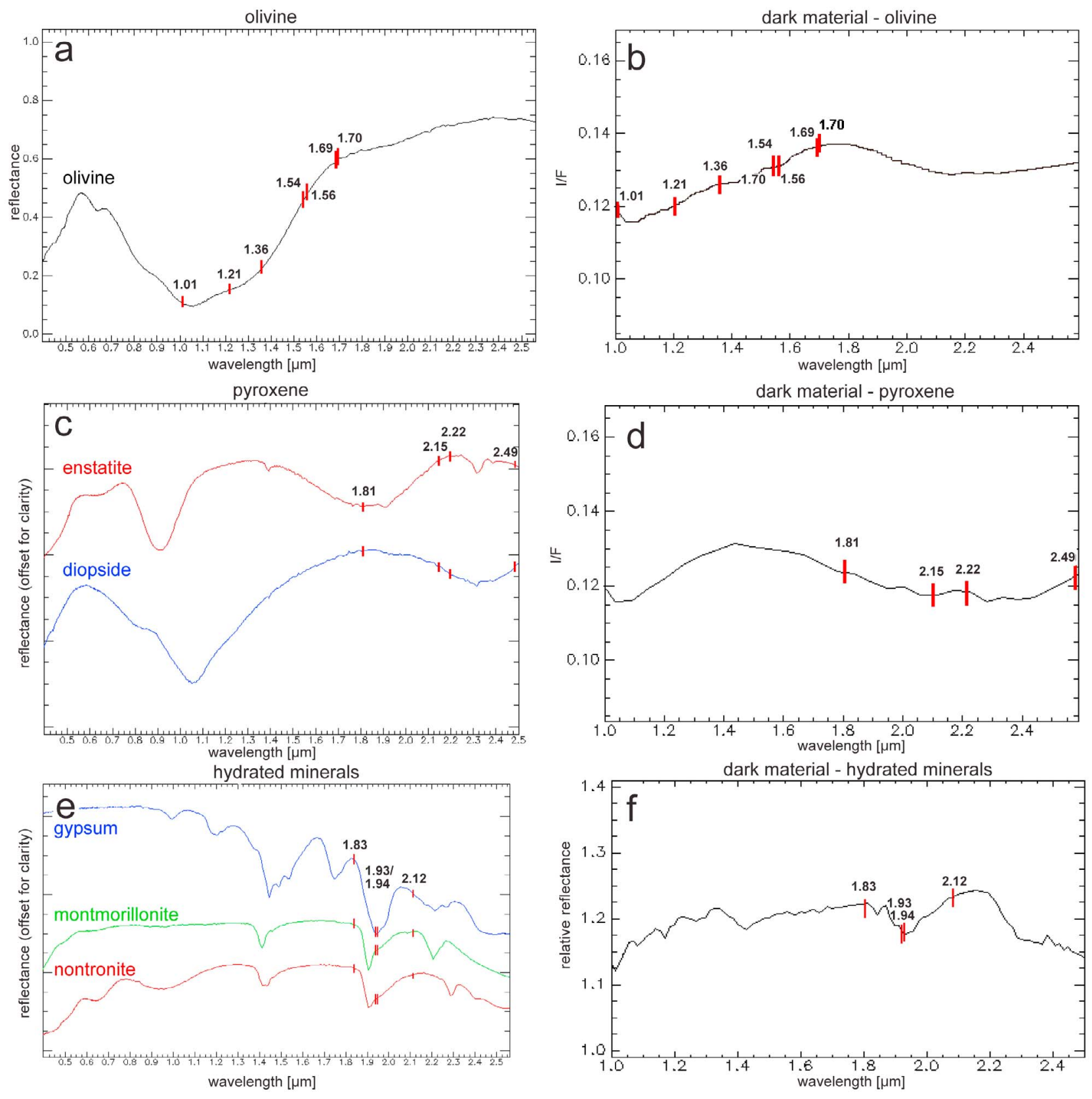

Figure 3. Library spectra derived from the ENVI spectral library compared to OMEGA spectra. Wavelength positions used for the spectral criteria calculation are indicated as red marks (see Table 1). (a) Library spectrum of olivine. (b) OMEGA spectrum of olivine. (c) Library spectra of low-calcium pyroxenes (LCP) and high-calcium pyroxenes (HCP). (d) OMEGA spectrum of pyroxene. (e) Library spectra of different hydrated minerals. (f) OMEGA spectrum of hydrated minerals.

mineral detection was a priori employed to search for olivines $\left[(\mathrm{Mg}, \mathrm{Fe})_{2} \mathrm{SiO}_{4}\right]$ and pyroxenes $\left[(\mathrm{Ca}, \mathrm{Fe}, \mathrm{Mg})_{2} \mathrm{Si}_{2} \mathrm{O}_{6}\right]$. The major question is whether all examined dark sediment deposits exhibit this mafic signature or whether there are some localities showing a different spectral signature.

[12] Figures 3b, 3c, and 3e show library absorption spectra samples of the minerals under discussion. Highcalcium pyroxenes (HCP) are represented by the spectrum of diopside and low-calcium pyroxenes (LCP) by enstatite. The wavelength positions of the applied calculations (see
Table 1) are indicated by red marks on the library and the sample OMEGA spectra. The spectral criterion of waterbearing minerals was used to analyze whether some parts of the dark material patches have undergone a chemical alteration, such as the physical or chemical absorption of water molecules in hydrated sulfates, hydrous hydroxides and certain phyllosilicates [Poulet et al., 2008].

[13] Additionally, it was checked with the aid of applicable spectral criteria whether $\mathrm{H}_{2} \mathrm{O}$ ice or $\mathrm{CO}_{2}$ ice [e.g., Forni et al., 2005] is abundant in the materials (see Table 1). 

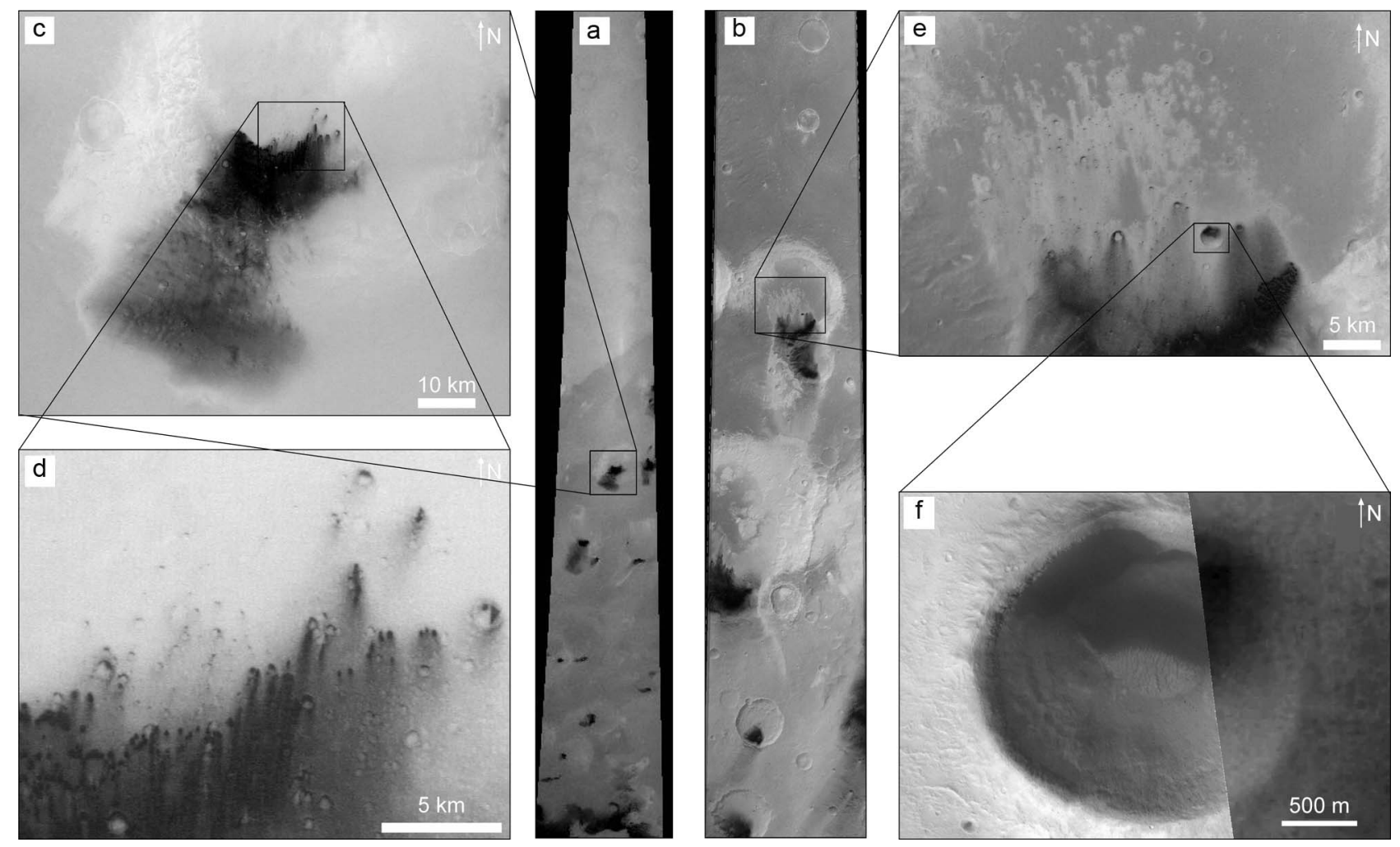

Figure 4. Indication of craters acting as a local sediment source. HRSC orbits (a) 1333_0000 and (b) 3297_0000 show dark material deposits appearing in the craters and emanating from there. (c) Zoom into HRSC 1333 0000 showing the dark patch of a $52 \mathrm{~km}$ diameter crater in Arabia Terra $\left(8.9^{\circ} \mathrm{N}, 11.1^{\circ} \mathrm{E}\right)$. (d) Zoom into the crater floor showing dark material emanating from smaller craters superimposed on the larger crater floor. (e) Zoom into HRSC 3297_0000 showing a $62 \mathrm{~km}$ diameter crater near Mawrth Vallis $\left(18.9^{\circ} \mathrm{N}, 345.5^{\circ} \mathrm{E}\right)$ and dark sediment emanating from smaller craters. (f) Subset of MOC R0701192 overlaid on HRSC showing a small crater comprising a dark layer exposed in the crater wall.

The presence of ice might corrupt the results and interpretation of the detection especially of hydrated minerals [Poulet et al., 2007].

[14] The method of mineral detection described above provides images in which color-coded signatures for absorption depths corresponding to the minerals of interest are overlaid on OMEGA orbits (e.g., see Figure 8). For the individual locations, at least two different OMEGA orbits (where available) were used to verify the results. Comparing images from several observations improves the chances of detecting and eliminating the residual influence of surface or atmospheric dust which might mask the mineralogical signature resulting in a featureless spectrum declining to higher wavelengths (blue slope). Atmospheric dust varies over time; thus, these spectral influences should have changed by the time of the next observation (see section 4.2). Surface dust coatings may also disappear in the meantime. If a "blue slope" is obvious in one observation and gone in the second, the conclusion is that the first observation was contaminated by dust and cannot be used for mineral detection. Correlating mineral spectra for both orbits provide the best verification. In addition to the mineral maps obtained by the ratio technique adapted from Poulet et al. [2007], the individual spectra of every dune deposit were analyzed as well. This is very important to avoid misinterpretations because the automated detection technique can yield ambiguous results in some cases, e.g., in terms of hydrated minerals and water ice detection (see section 4.2). To enhance the spectral signature of the dark sediment, spectral ratios are generated by dividing the $\mathrm{I} / \mathrm{F}$ of atmospherically corrected spectrum of the dark material by a reference spectrum. The latter was obtained on the same OMEGA orbit (same atmospheric path length and instrumental effects) from a nearby dusty region exhibiting no mafic mineral features. Thus, residual atmospheric and instrumental effects were canceled out, leaving the spectral properties of the material of interest in the ratio spectrum [Mustard et al., 2005].

[15] We assessed the modal mineralogy of selected dark deposits by means of the nonlinear unmixing model described in detail by Poulet et al. [2009a, 2009b] which is based on the radiative transfer model of Shkuratov et al. [1999] and was adapted to basaltic surfaces by Poulet and Erard [2004]. A skeleton library consisting of optical constants of several end-members to account for all major igneous minerals is used: LCP (pigeonite), HCP (diopside), Mg-rich olivine (Fo90, forsterite), and plagioclase (labradorite) with dark oxide (magnetite) inclusions embedded. Martian dust was added to represent the mobile dusty component identified by its ferric bands detected in the visible part of the spectra. As discussed by Poulet et al. 

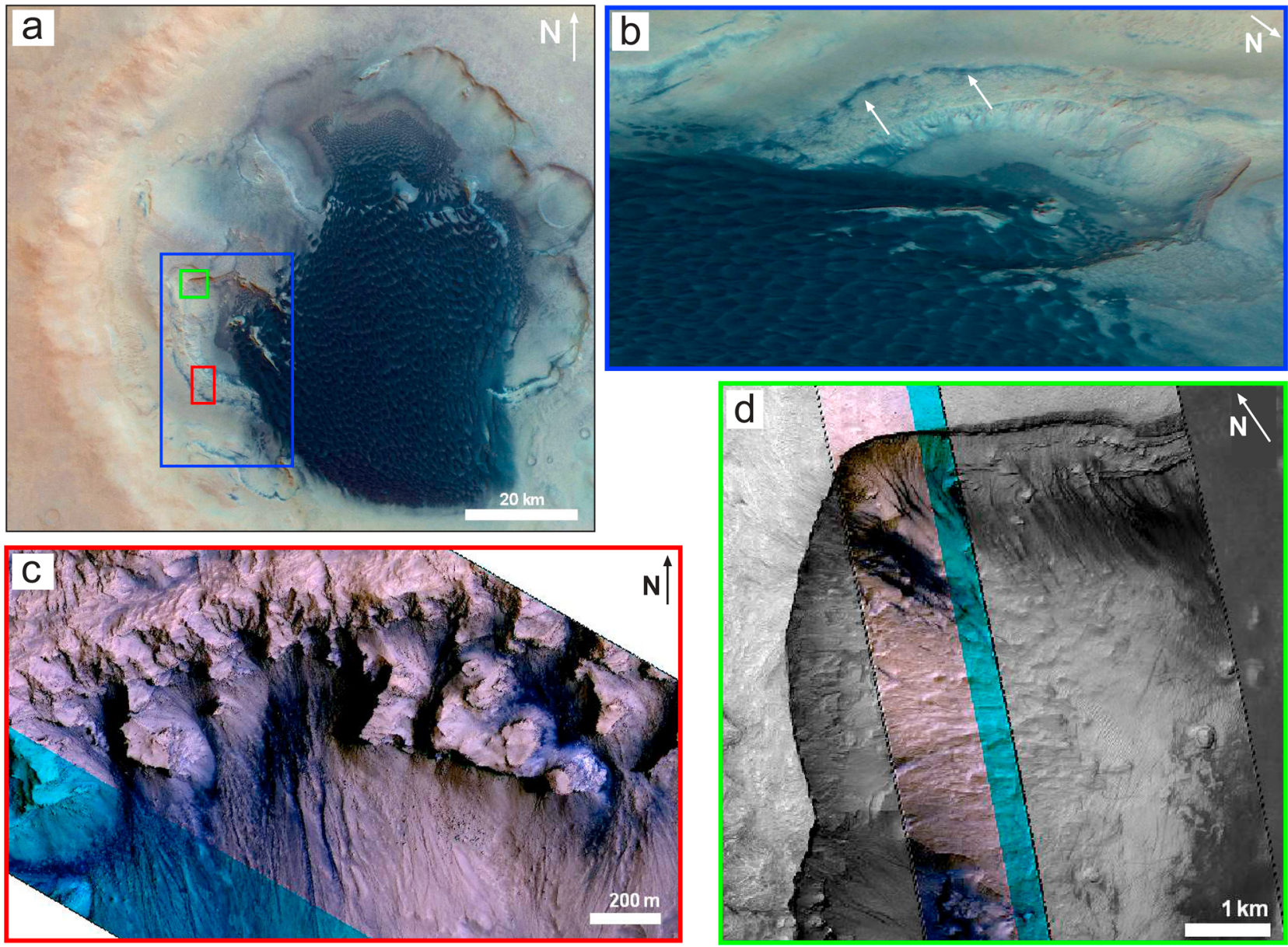

Figure 5. Dark layers exposed in the walls of a pit within Rabe crater. (a) Plan view of Rabe crater $\left(43.9^{\circ} \mathrm{S}, 34.8^{\circ} \mathrm{E}\right.$; HRSC color composite 2441 0000), rectangles indicate the positions of Figures 5b, $5 \mathrm{c}$, and 5d, identifiable by their outline colors. (b) Perspective view of the intracrater pit, same HRSC orbit as Figure 5a. (c and d) Dark material emanating from dark layers exposed in the pit wall (subsets of HiRISE color image PSP 005646_13460 in Figure 5d overlaid on red channel of the same image).

[2009a, 2009b], the particle size of the dust component is fixed at $5 \mu \mathrm{m}$, and the olivine abundance is given assuming particle size fixed at $100 \mu \mathrm{m}$.

\subsection{Uncertainties}

[16] Several factors might lead to misinterpretations of the mapping results. The presence of water ice and $\mathrm{CO}_{2}$ ice can influence the detection of hydrated minerals. Both ices have an absorption band centered at $2 \mu \mathrm{m}$ that may affect the detection of hydrated minerals whose diagnostic absorption bands are centered at $1.9 \mu \mathrm{m}$. Mafic mineral detection can be influenced by the presence of ice [Poulet et al., 2007] because the characteristic $\mathrm{H}_{2} \mathrm{O}$ ice absorption at $1.5 \mu \mathrm{m}$ and the $\mathrm{CO}_{2}$ absorption at $1.43 \mu \mathrm{m}$ lie within the spectral range that is characteristic for pyroxene and olivine. Therefore, pixels showing ice absorptions are disregarded in the determination of dark sediment mineralogical composition. Fine-grained coatings on the surface might mask the spectral signature of a material in the visible and near-infrared wavelength range [Christensen et al., 1998; Singer and Roush, 1983]. Due to the increasing transparency of surface coatings at longer wavelengths, this effect is less important in the near-infrared than in the visible spectral range, so that pyroxene and olivine can be detected despite the presence of a surface coating [Poulet et al., 2007]. Poulet et al. [2007] even interpreted the resulting blue slope of the spectrum as an indirect detection of basaltic materials such as pyroxene and olivine. However, due to the uncertainty inherent in this interpretation, spectral ratios were computed in this work to identify a possible mafic signature. Dark sediments exhibiting a strong blue slope spectrum and lacking an indication of mafic composition in the spectral ratio are interpreted as dust covered (labeled as "dust" in Figure 12). The influence of aerosols (atmospheric dust) has a comparable blue slope expression in the spectral shape. However, this effect is highly variable with time. Thus, the analysis of multiple OMEGA observations acquired at different times, and the comparison of the different results, permitted verifying temporal variations and selecting unaffected observations. Furthermore, the influence of atmospheric dust is strongest in the visible wavelength range and decreases with increasing wavelength due to the growing transparency of aerosols [Singer and Roush, 1983]. This small influence allows neglecting atmospheric variations in 

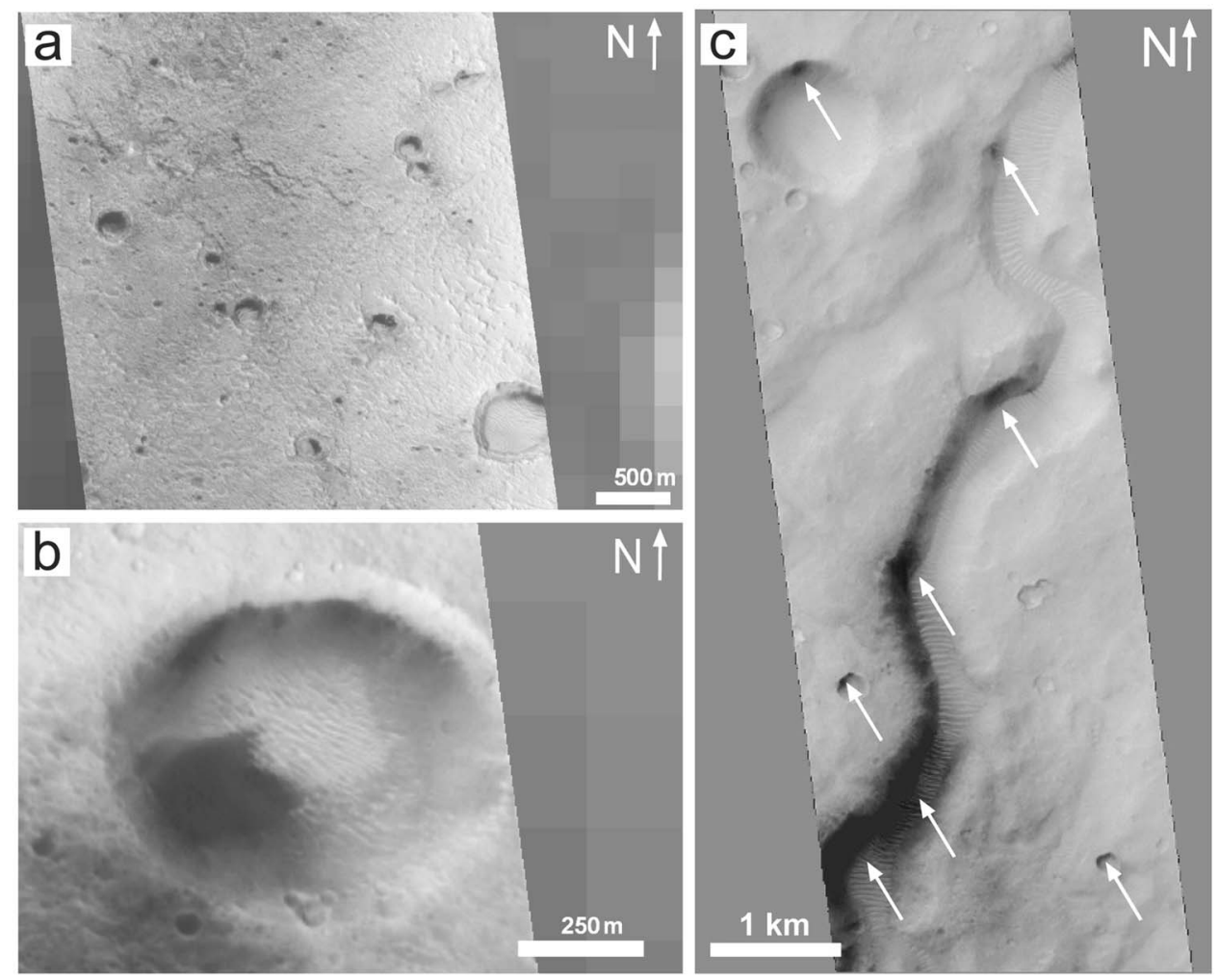

Figure 6. Dark features exposed in sun-facing walls. (a and b) Dark layers exposed in the walls of small impact craters in Arabia Terra (near $16.1^{\circ} \mathrm{N}, 344.5^{\circ} \mathrm{E}$; subframes of MOC image E0500437). (c) Dark features exposed in the walls of channels and craters close to Ares Vallis showing remarkable similarity to the dark layers described above $\left(6.8^{\circ} \mathrm{N}, 336.9^{\circ} \mathrm{E}\right.$; subframe of MOC image 2000929).

mineral detection in the near-infrared range. The grain size distribution as well as mineral mixtures has a strong influence on the absorption band depth. Especially the discrimination between forsterite and fayalite is critical with varying grain size because of the strong influence on the $1 \mu \mathrm{m}$ band [Poulet et al., 2007]. Poulet and Erard [2004] and Poulet et al. [2007] present detailed simulations applied to test the influence of mineral mixtures and grain sizes on the spectral shape of minerals. In addition to other factors, increasing grain sizes result in decreasing depths of olivine absorption, making it difficult to discriminate between coarse-grained forsterite and fine-grained fayalite, for example. However, for this analysis discriminating between the olivine types is not a major issue. Thus, the forsterite and fayalite criteria were merged into one group for olivine detection.

\section{Analyses of Dark Layers}

[17] The conventional assumption about the relationship between dark sediment and depressions is that the material might be blown into as well as out of the depressions [e.g., Christensen, 1983; Edgett and Malin, 2000; Greeley et al., 1993; Jaumann et al., 2006; Malin and Edgett, 2001]. Depressions may act as sediment traps into which the aeolian material is blown to accumulate on the depression floor. Once the sediment is deposited on a crater floor, it may also act as a source, meaning that material is blown out or deflated, frequently forming wind streaks [Thomas et al., 1981].

[18] In view of the aeolian character of transportation and the huge number of traps, it might appear evident that the trapping function of craters is the main mechanism for accumulating the dark sediments. However, dark deflational wind streaks indicate in most cases that material is blown out of the craters rather than deposited in them. The latter case can be observed in places where a number of craters with dark sediments lie close to each other and a dark deflational wind streak from an upwind crater reaches its downwind neighbor, delivering material into its interior (e.g., crater in lower left portion of Figure 4b).

[19] The lack of examples for material being supplied from outside a crater requires an alternative material source. Central and western Arabia Terra present good examples for regions, which look completely "clean" of dark sediment upwind of the craters. The material solely appears inside and downwind of these craters, forming visible dark dunes and wind streaks. The HRSC orbits 3797 0000 and 1333_0000 shown in Figure 4 are examples of that situation in Ârabia Terra (also described by Edgett [2002]). There, the material seems to originate directly in the crater itself. Figures $4 d$ and 4e show that the floors of the larger craters are blotched by numerous smaller craters. It is noticeable that the dark sediment in these craters solely appears downwind of the smaller craters. The material seems to originate from a sediment source just beneath the crater floor, which was cut open by the smaller craters. 


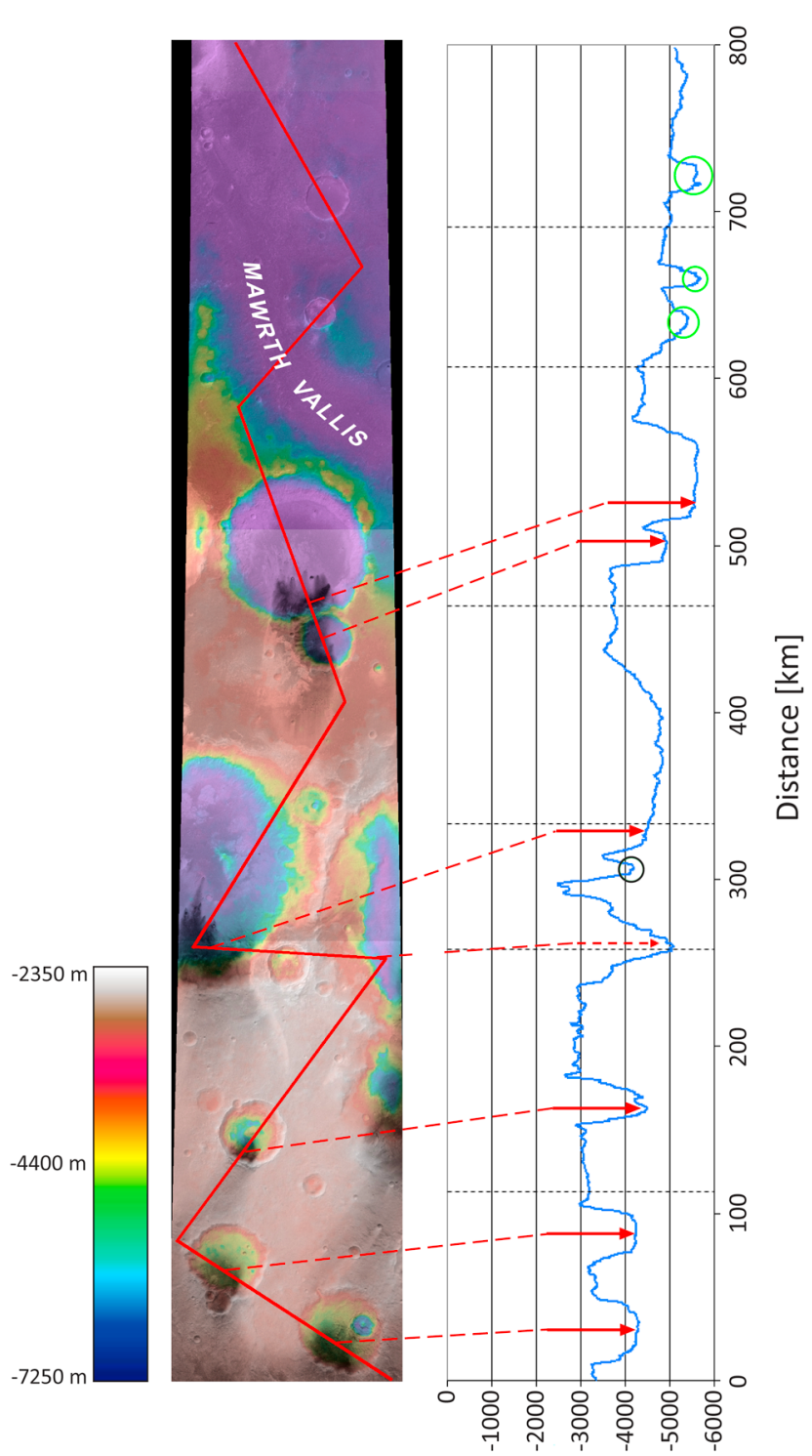

[w] ио!ฺе^리

Figure 7. Analysis of the elevations of dark material craters and their surrounding. (left) Color-coded HRSC DTM overlaid on HRSC nadir image of orbit 3297_0000 (image width is about $104 \mathrm{~km}$ ). The red line indicates the course of the profile from south to north. (right) Corresponding profile along the craters with and without dark sediment at different elevations. Red dotted lines connect dark material sites in the left-hand image and the right-hand profile (note the dotted red arrow at about $250 \mathrm{~m}$ distance marks the western part of Trouvelot crater, which also comprises dark dunes). The black circle marks a crater just above the dark layer level. The green circles marks a valley and craters of lower elevation than the dark material craters which do not show any evidence of dark sediment. The black dotted lines indicate the breaks in the profile.

[20] MOC narrow-angle images of small craters (Figure 4f) reveal dark layers exposed in the crater walls. Such layers can be observed in a number of craters. At Rabe crater (Figure 5), an intracrater pit provides illuminating insights into the morphology of the dark layers, as previously described by Fenton [2005a, 2008]. High-resolution images disclose dark gully like streaks extending downwall, indicating erosion of these dark layers and transportation of material into the crater's interior (Figures $5 \mathrm{c}$ and $5 \mathrm{~d}$ ). Thus, the dark gullies could be pathways of sand transport from the pit wall to the interior dunes in Rabe crater [Fenton, 2005a, 2008; Tirsch et al., 2007]. HRSC and HiRISE false color composites reveal that the blue color of the dark layers and the gully material resembles that of the dark dune material inside the crater (see Figure 5). This color correlation suggests that the layers have a similar mineralogical composition compared with that of the dune material inside the crater. Analyses of corresponding stratigraphic units using color composites were previously performed by Loizeau et al. [2007a, 2008], demonstrating that this method produces reliable results.

[21] A comparison of the numerous image data indicating exposed dark layers reveals that these features are predominantly situated in the sun-facing walls. In Figures $4 \mathrm{e}$ and $4 \mathrm{f}$ as well as in Figure 6 the dark layers are exposed in the northern wall. Since these images represent northern hemisphere localities, the northern, equator-facing wall is the one that experiences the maximum insolation. Similar characteristics can be observed in the walls of numerous narrow channel-like structures that are sometimes located in the immediate vicinity of craters and show dark features in their walls, which resemble the described dark layers in albedo and elevation level (Figure 6c). Although we cannot exactly understand the transport pattern for these dark sediments, the observed proximity suggest us the occurrence of a generic association between these dark exposures. Future spectral analyses of these channel features are needed to prove this hypothesis.

[22] To obtain an impression of the relative elevation of craters with and without dark sediment exposure we analyzed HRSC orbit 3297 0000. For this analysis, a profile was generated from HRSC DTM data across the entire orbit, as shown in Figure 7. The same orbit is shown in Figure 4b, where dark material seems to have its origin in a sediment source beneath the crater floors, cut by smaller craters superimposed onto the larger crater's floor. Unfortunately, the DTM does not resolve the exact topography of the smaller craters supposed to have cut through the subsurface layer, because these smaller craters are beyond the stereo resolution. Nevertheless, the profile provides sufficient insight into the topography variations of the dark sediment patches in the craters. The profile shows that there is an elevation variation of up to $1337 \mathrm{~m}$ between craters floors from where dark material emanates (indicated by red arrows). One crater at $-4174 \mathrm{~m}$ in the middle of the profile shows no indication of dark sediment (indicated by a black circle). This crater lies just above the upper level of the proposed dark layer in this region and indicates its upper margin. In the northern part of the observation area there are craters at similar and lower elevations as the dark material craters but do not show any indication of dark material at all (marked by green circles). This situation might be explained by the removal of the dark layer due to fluvial erosion caused by the Mawrth Valles valley system [e.g., Bishop et al., 2008a, 2008b; Mangold et al., 2010a; Michalski et al., 2007], which covers the northern part of the area. However, we do not see dark 

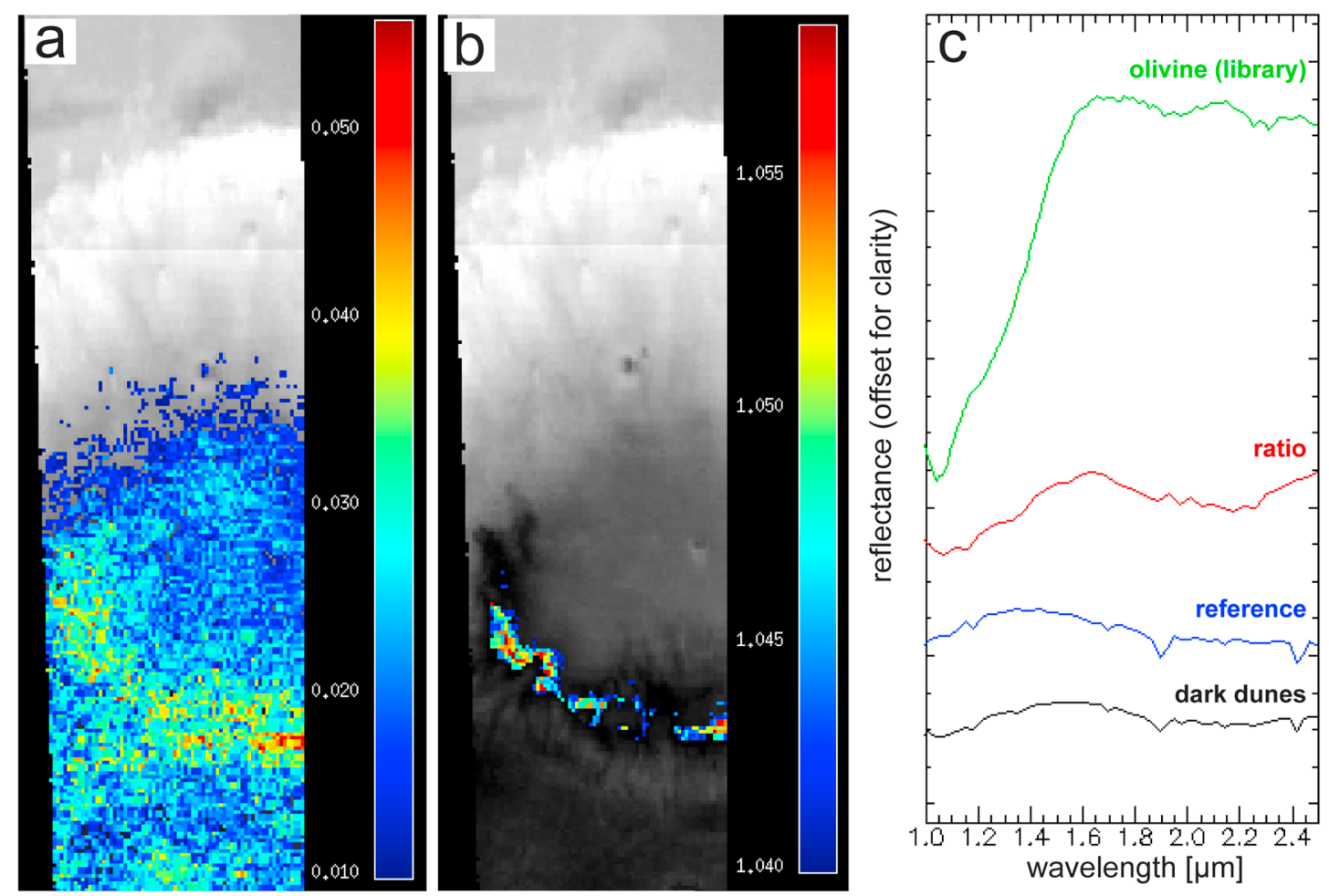

Figure 8. Results of the OMEGA spectral analysis of dark sediment in Dawes crater (Terra Sabea, $9.2^{\circ} \mathrm{S}$, $38^{\circ} \mathrm{E}$; ORB2384_4). (a) Mapping of pyroxene inferred from the depth of the $2 \mu \mathrm{m}$ band. (b) Mapping of olivine inferred from the $1 \mu \mathrm{m}$ band. (c) OMEGA ratio spectrum (red) of dark material (black) to reference spectrum (blue) compared to library spectrum of olivine (green).

layers exposed at the rims of Mawrth Valles, which might have been left behind. Alternatively, the layer might dip to the north below $-5600 \mathrm{~m}$. Hence, if there is indeed a dark sediment source beneath the surface its elevation and thickness might vary regionally. An alternative explanation might be an irregular multilayer source at different elevations (see section 6). Since we cannot find any geological evidence strengthening of weakening any of these scenarios, all of them should be seen as working hypotheses. This geologic setting is particularly prevalent in Arabia Terra and Xanthe Terra. Especially the western and central regions of Arabia Terra provide numerous examples of dark material emerging from crater floors blotched by smaller craters. This region seems to be ideally suited to exhibit and preserve these features, probably due to its elevation and the occurrence of moderately degraded craters. It cannot be ruled out that similar geomorphological signs have been obliterated due to erosion or coverage by regolith in more degraded craters, e.g., in the older southern terrains [Carr and Head, 2009]. The northern lowlands generally lack this configuration of crater-blotched impact crater floors.

\section{Mineralogy of Dark Aeolian Sediment}

[23] A careful spectral analysis was performed for every location. The OMEGA data used for the respective localities are listed in the auxiliary material. Figure 8 shows the mapping result for Dawes crater located in Terra Sabea $\left(9.2^{\circ} \mathrm{S}\right.$, $\left.38^{\circ} \mathrm{E}\right)$. The variation of band depth depends on the relative abundance and grain size of the minerals [Poulet et al., 2005]. In Dawes crater as well as in many other localities, pyroxene is the dominant mineral. The strongest pyroxene absorption is mapped in areas where the dark sediment accumulates in dunes due to the higher abundance of minerals grains. The surrounding sand sheets exhibit shallower pyroxene bands. Olivine minerals occur solely in the dune areas and not in the surrounding thin windblown sand sheets. The ratio of the dark dune spectrum to the reference spectrum emphasizes the broad $1 \mu \mathrm{m}$ olivine absorption band (see Figure $8 \mathrm{c}$ ). Furthermore, the deep $2 \mu \mathrm{m}$ pyroxene band is clearly visible in the ratio spectrum. If pyroxene alone were involved, the $1 \mu \mathrm{m}$ absorption band would be much narrower and incline faster. Thus, the spectra confirm the mapping results, which imply that the dark dunes in Dawes crater are composed of pyroxene and olivine.

[24] A similar result was obtained for Trouvelot crater, located in Oxia Palus $\left(16.3^{\circ} \mathrm{N}, 346.5^{\circ} \mathrm{E}\right.$, western Arabia Terra). Pyroxene is the dominant mineral, while olivine solely occurs in the dark patch in the smaller crater superimposed onto Trouvelot's crater floor. The band depth of olivine in that area is very shallow. However, the spectral ratio confirms the detection of olivine in Trouvelot crater. At the eastern margin of that intracrater patch there is a small area showing absorption features at 1.4, 1.9, and $2.3 \mu \mathrm{m}$ corresponding to hydrated minerals (Figures 9c and 9e). The overall shape of that spectrum best matches to vermiculite, 

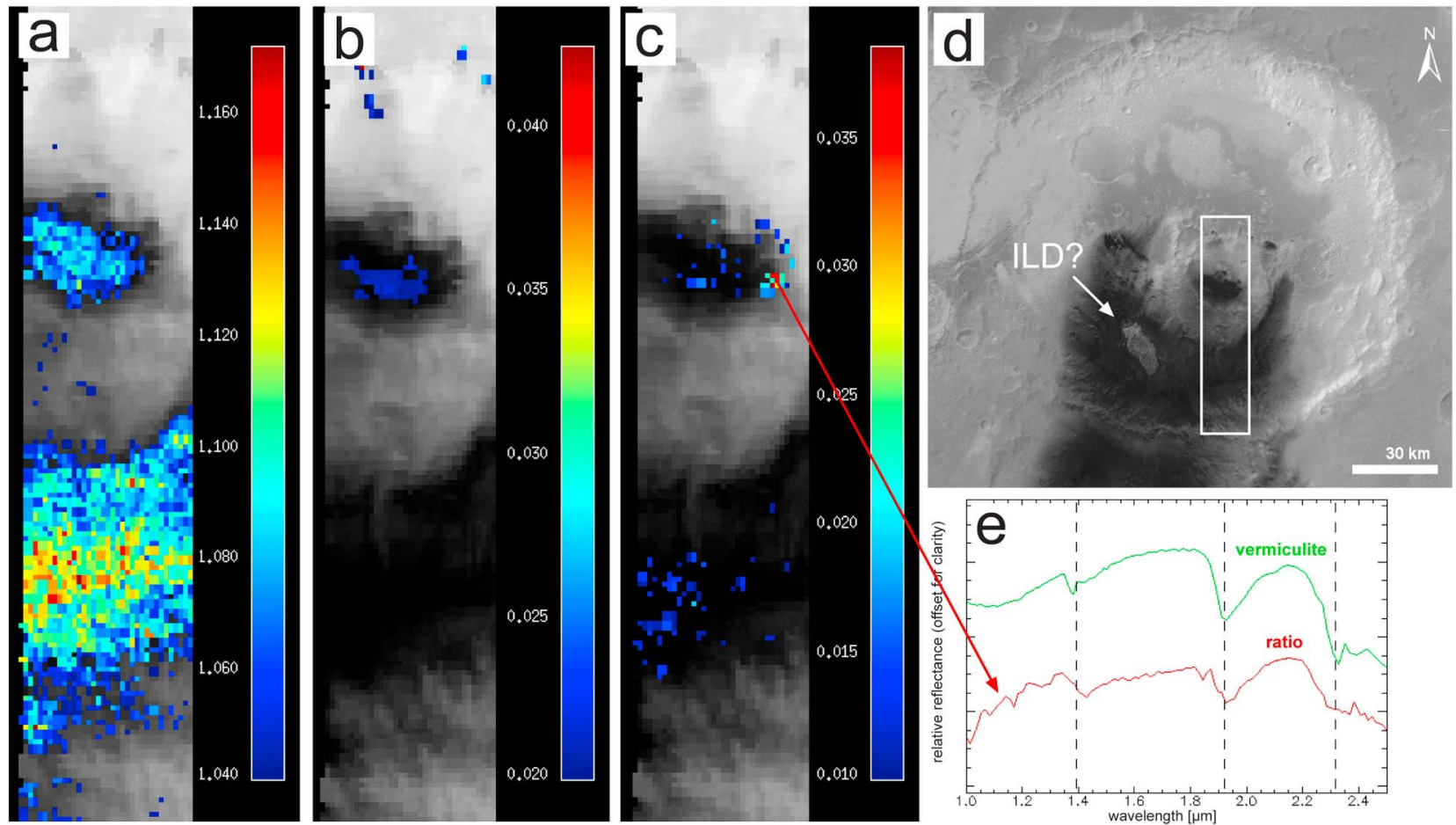

Figure 9. Results of the OMEGA spectral analysis of dark material in Trouvelot crater (western Arabia Terra, $16.3^{\circ} \mathrm{N}, 346.5^{\circ} \mathrm{E}$; ORB1260_2). (a) Mapping of pyroxene inferred from the depth of the $2 \mu \mathrm{m}$ band. (b) Mapping of olivine inferred from the $1 \mu \mathrm{m}$ band. (c) Mapping of hydrated minerals inferred from the depth of the $1.9 \mu \mathrm{m}$ band. (d) Context image of Trouvelot crater showing footprint of OMEGA subset in Figures 9a, 9b, and 9c (HRSC mosaic of 32680000 and 3275 0000). (e) OMEGA spectrum of hydrated minerals showing the absorption band near $1 . \overline{9} \mu \mathrm{m}$ detected at the eastern margin of the dark patch within the smaller crater inside Trouvelot crater.

which is a phyllosilicate resulting from the alteration of basaltic rocks [Deer et al., 1963; Matthes, 2001].

[25] The occurrence of hydrated minerals in Meridiani Planum and nearby terrains has been reported by several authors [e.g., Christensen et al., 2004; Gendrin, 2005; Poulet et al., 2008]. Light-toned layered outcrops (also described by Edgett [2002]) are found further to the southeast on Trouvelot's crater floor, bearing a striking resemblance to the so-called Interior Layered Deposits (ILDs). Many authors analyzed such deposits in Valles Marineris and the Chaotic Terrains on Mars [e.g., Chapman et al., 2007; Fueten et al., 2005; Nedell et al., 1987; Sowe et al., 2007]. Different kinds of sulfates were found on the flanks of the ILDs [Hauber et al., 2006; Roach et al., 2007]. These hydrated minerals point to an aquatic influence during the genesis of the layered deposits [Gendrin, 2005]. If this hypothesis is right, it could be likely that the light-toned layered outcrops at Trouvelot crater are of similar origin. Thus, if the dark material had emerged already at that time, these aquatic processes could be the cause of the hydration of the dark sediment in this locality as well. However, the dark aeolian sediments are unoxidized and unaltered. Thus, one might ask why not the entire dark material was affected by hydrous alteration because a lacustrine environment would span the whole crater floor acting as a lake in that case. In addition to Trouvelot crater, hydrated minerals were detected in a crater near Mamers Valles and in some craters in Meridiani Planum (see Figure 12a). The occurrence of hydrated minerals in western Arabia Terra was previously reported by several authors [e.g., Arvidson et al., 2005; Gendrin, 2005; Jouglet et al., 2007; Loizeau et al., 2007b; Poulet et al., 2005, 2008]. Loizeau et al. [2007b] found large bright outcrops comprising phyllosilicates near Mawrth Vallis. One hypothesis says that the formation of these phyllosilicate-rich units could result from the alteration by liquid water of volcanic ash deposits [Loizeau et al., 2007b]. These findings support the local alteration hypothesis of the dark sediments in Trouvelot crater. Poulet et al. [2008] detected hydrated minerals colocated with mafic materials in craters in Meridiani Planum and western Arabia Terra. Hydrated materials cover large segments of the etched terrain in Meridiani Planum (unit E at Poulet et al. [2008]). Poulet et al. [2008] reported that the dark pyroxene-bearing dunes overlay this brighter etched terrain. They suppose that the spectra of the OMEGA pixels of these localities represent a mixture of pyroxene-bearing dune material and the hydrated materials of the etched terrain. This scenario may also apply to the craters in Meridiani Planum (see Figure 12a) where we detected hydrated minerals, because they are located very close to the craters analyzed by Poulet et al. [2008]. Unfortunately, the lack of high-resolution image data for these craters makes it impossible to prove this theory. In the case of Trouvelot crater (Figure 9), further analyses might show whether the 

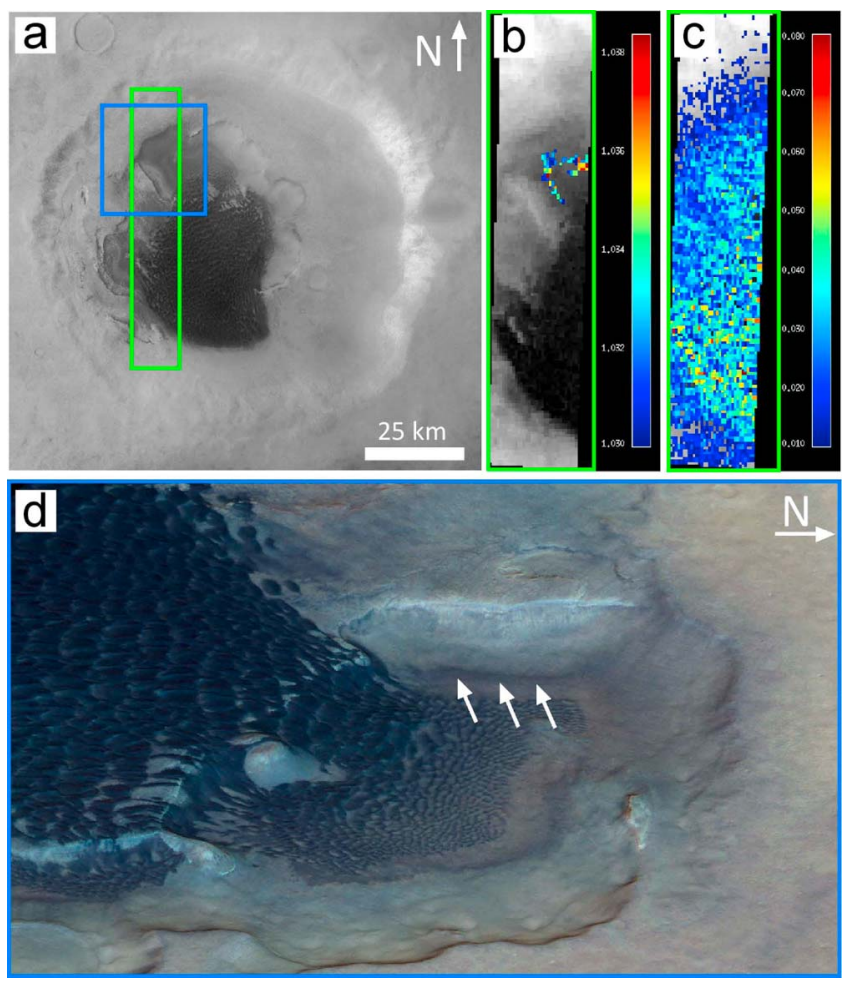

Figure 10. Spectral analysis of a dark layer exposed in an intracrater pit at Rabe crater $\left(43.9^{\circ} \mathrm{S}, 34.8^{\circ} \mathrm{E}\right)$. (a) Plan view of Rabe crater showing the footprints of Figures 10b, 10c, and $10 \mathrm{~d}$, identifiable by their outline colors (HRSC nadir mosaic of 4280_0000, 4269_0000 and 4258_0000). (b) Mapping of olivine inferred from the $1 \mu \mathrm{m}$ absorption band. (c) Mapping of pyroxene inferred from the $2 \mu \mathrm{m}$ absorption band. (d) HRSC perspective view toward the west showing the dark olivine-bearing layer as detected in Figure 10b (HRSC color composite 2441_0000).

hydration spectral signature is associated with the dark sediment itself, caused by hydrated material underneath the dunes, or shining through a thin dark sand sheet. This can be done when high-resolution image data become available for this locality.

[26] Olivine not only occurs rarely but also appears predominantly in the material of small active-looking fresh dunes and sand sheets. Moreover, in the case of Rabe crater (Noachis Terra, $43.9^{\circ} \mathrm{S}, 34.8^{\circ} \mathrm{E}$ ), olivine was detected in a dark layer exposed in the wall of an intracrater pit (Figure 10) by spectral ratios of dark layer material.

[27] Material coming out of the walls might be very fresh, having not been exposed to the atmosphere for a long time. This is in contrast to the pyroxene-rich material that constitutes the intracrater deposits. It takes at least $2 \times 10^{6}$ years to accumulate massive sand deposits higher than $>300 \mathrm{~m}$ on Mars, a figure deduced from terrestrial analogues by Breed et al. [1979] which also applies to the Rabe crater dune field on Mars (dune field volume: $77-1143 \mathrm{~km}^{3}\left[\mathrm{MCD}^{3}\right.$, Hayward et al., 2007a]; dune field height: at least $287 \mathrm{~m}$ as measured in the MOLA topography map). During this long dune development, the dark minerals were exposed to the atmosphere, and thus, to disintegration and alteration progresses. Because they crystallize at higher temperatures, olivine minerals, having a lower density $\left(3.27-3.37 \mathrm{~g} / \mathrm{cm}^{3}\right)$, are less stable at low Martian temperatures and weather earlier to smaller grain sizes than pyroxene minerals (density $3.2-3.88 \mathrm{~g} / \mathrm{cm}^{3}$ ), although both minerals are of the same hardness [Matthes, 2001]. In mineral mixtures, smaller grains are more difficult to detect than coarser grains [Poulet et al., 2007]. Grain size is particularly critical for olivine detection because it strongly affects the $1 \mu \mathrm{m}$ band due to the interaction of the shorter wavelength with the particle size [Poulet et al., 2007]. Grain size differences of individual olivine and pyroxene particles result in shallower $1 \mu \mathrm{m}$ absorption band depths for smaller particles (see section 4.2). Thus, small olivine grains are the first to disappear from spectral signatures. The occurrence of olivine in the fresh dark layer and the lack of olivine in the remaining dune field support the suggestion of relative young and fresh olivine particles, which quickly break down into smaller grain sizes. It also let suggest that pyroxene particles are more stable with time. An additional indication for that scenario is the absence of olivine in the other huge dune fields but its occurrence in small unconsolidated dunes, which might be younger than the huge and consolidated ones [cf. Tirsch, 2009]. Thus, the low prevalence of olivine in the spectra of the dunes might reflect its faster thermal and mechanical erosion under Martian conditions.

[28] Using high-resolution CRISM data, spectral analyses of the dark layers exposed in crater walls confirm the suggestion that the dark wall material and the dune material are of similar mineralogical composition. Spectra of dark sediment emanating from a dark layer exposed in the wall of a crater at Terra Sirenum $\left(39.3^{\circ} \mathrm{S}, 196.0^{\circ} \mathrm{E}\right.$, Figure 11) exhibit obvious signatures of olivine and pyroxene. Several dark dunes develop at the bottom of this crater wall directly downslope from where dark material emerges from the dark layer. Spectral analyses of the dunes reveal an obvious pyroxene content. However, the dune material shows no strong olivine absorptions. This observation is similar to the situation in Rabe crater mentioned above. The lack of strong olivine signatures in the dunes of this crater could be an additional indication of the disappearance of olivine from dark materials exposed to the surface for a certain time due to its faster disintegration to smaller grain sizes. This grain size effect (see above) is the reason why so little olivine has been detected in the dunes. In this scenario, the wall material is of coarser grain size than the dune material. This seems reasonable because the grain size of the layered wall material might not yet been reduced, whereas the dune material is already comminuted by mechanical splitting. Additionally, the dune material is mixed with pyroxene, which complicates the detection of olivine (see section 4.2). Consequently, the method employed may not accurately identify olivines in mixed dune material if its grain size is in the micrometer range [Poulet et al., 2007]. However, the concurrent mafic composition results establish a mineralogical association between the wall and the dune material. Accordingly, the dark layers may be the local sources of the intracrater dune material [see also Tirsch et al., 2007, 2009].

[29] A global view of the mineralogy of all examined dune fields and sand sheets is given in Figure 12a. Pyroxene is the dominant mineral in the dark sediment deposits. Olivine minerals were detected in 21 localities. In each, 
olivine exists in association with pyroxene. This is consistent with the results of Poulet et al. [2007], who found that olivines on Mars mostly occur in combination with pyroxene. Only seven localities show no obvious mafic spectral signature. Here, the flat and featureless spectral shape indicates the presence of a dust layer on top of the dunes and dune fields. In three localities at higher latitudes, the mineralogical composition of the dark sediment could not be assessed because layers of water ice covered the surface of the dark material, as indicated by the spectra. However, in 59 out of 70 localities where dark material occurs, a mafic composition comprising pyroxene and olivine could be
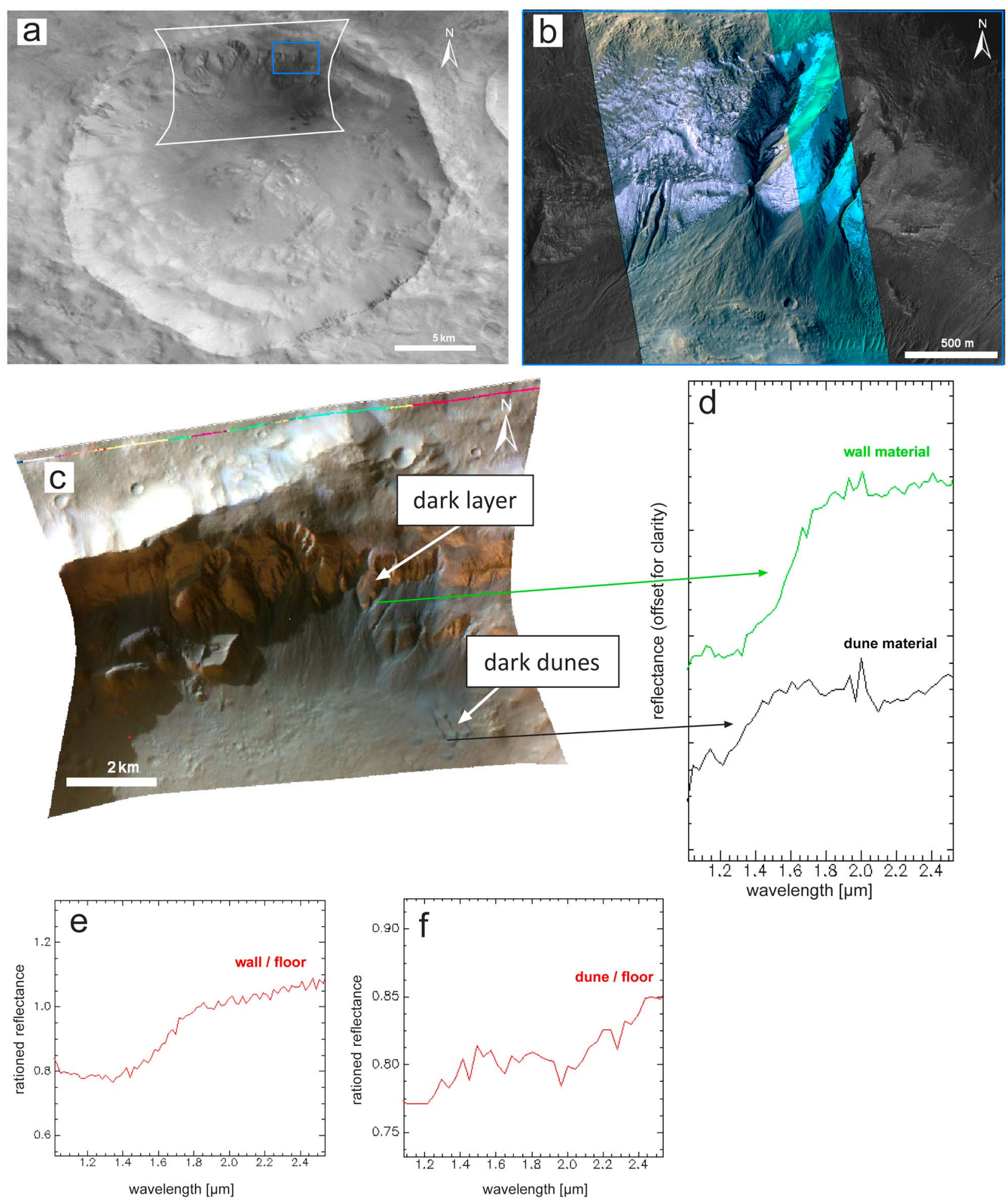

Figure 11

13 of 25 

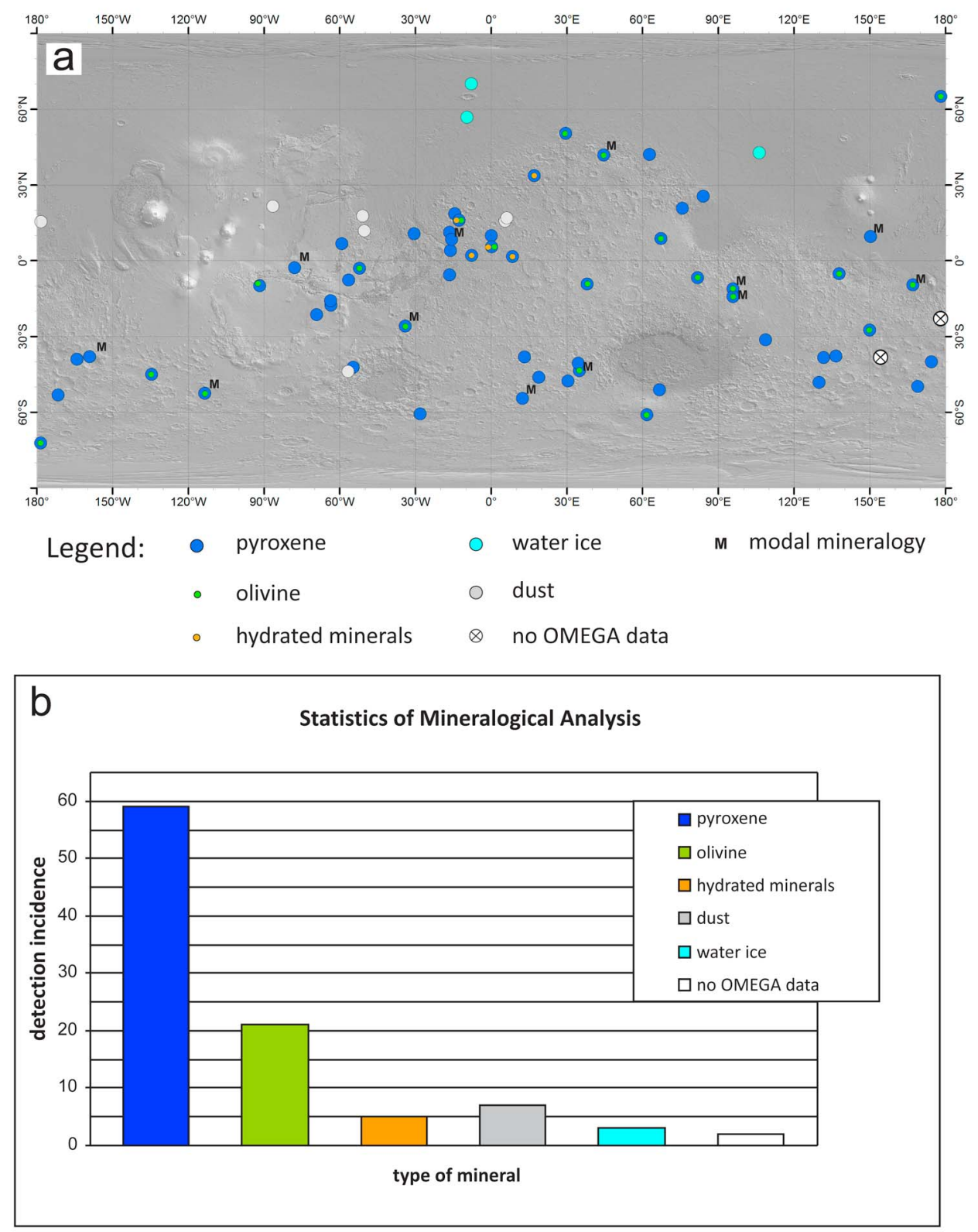

Figure 12. Results of the mineralogical analysis. (a) Global consideration of the mineralogical composition of dark intracrater deposits (background is MOLA topography map). In general, the homogeneous distribution indicates no correlation between mineralogical composition and geographical location suggesting a similarity in material origin (see text for further discussion). (b) Statistics of the mineralogical analysis.

Figure 11. CRISM spectral analysis of dark sediment emanating from a dark layer exposed in a crater wall. Reflection spectra of dark material emanating from the crater wall show a similar mafic composition as the dune material. (a) Context image of the crater in Terra Sirenum $\left(39.3^{\circ} \mathrm{S}, 196.0^{\circ} \mathrm{E}\right)$ showing the approximate footprints of Figures $11 \mathrm{~b}$ (blue) and $11 \mathrm{c}$ (white) (HRSC 2476_0000). (b) Close view of the dark layer exposed at the crater wall showing the dark sediment emerging from the layer (subset of HiRISE PSP_001684_1410). (c) CRISM observation showing the crater wall and the dark dunes in front. Green and black arrows mark the locations where the wall and dune spectra of Figure 11d were taken. The spectral peaks around $2 \mu \mathrm{m}$ are due to an over correction caused by the atmospheric correction process and are not indicative spectral features (CRISM FRT00003266, color composite of bands $13(1.08 \mu \mathrm{m}), 87(1.5 \mu \mathrm{m})$, and $233(2.5 \mu \mathrm{m})$ ). (d) Reflection spectra of wall material (green curve) and dune material (black curve). The wall material spectrum exhibits pyroxene as well as strong olivine absorptions, whereas the dune material spectrum shows a pyroxene signature only. (e) CRISM spectral ratio of wall material and crater floor emphasizing the olivine signature of the dark wall material. (f) CRISM spectral ratio of dune material and crater floor emphasizing the pyroxene signature of the dark dune material. 

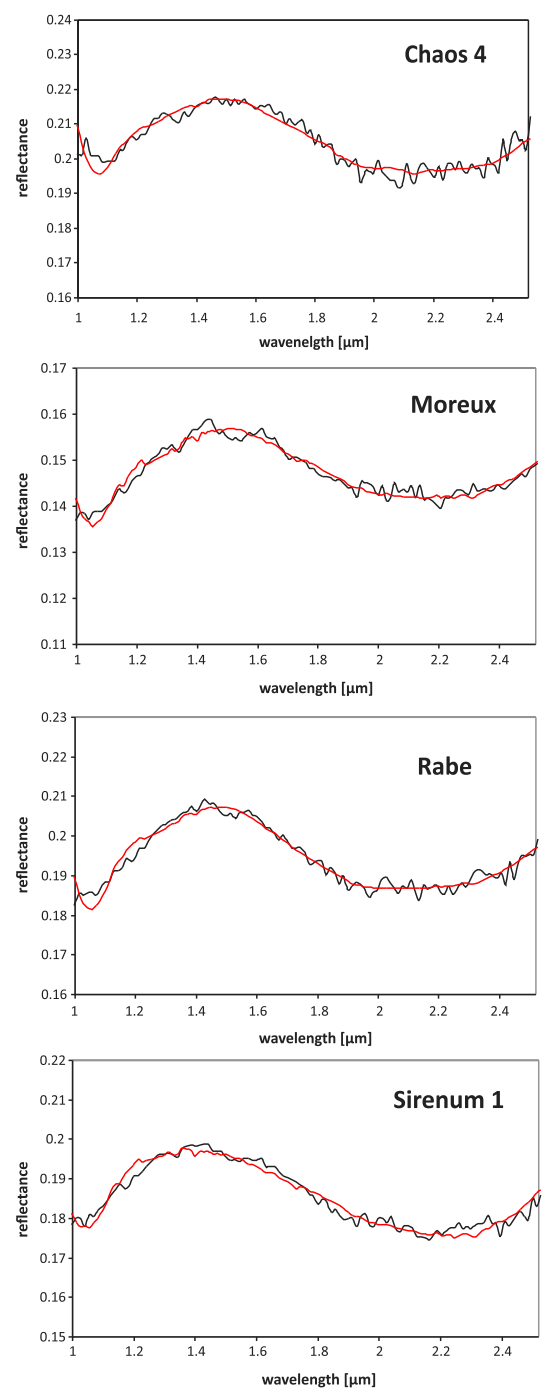
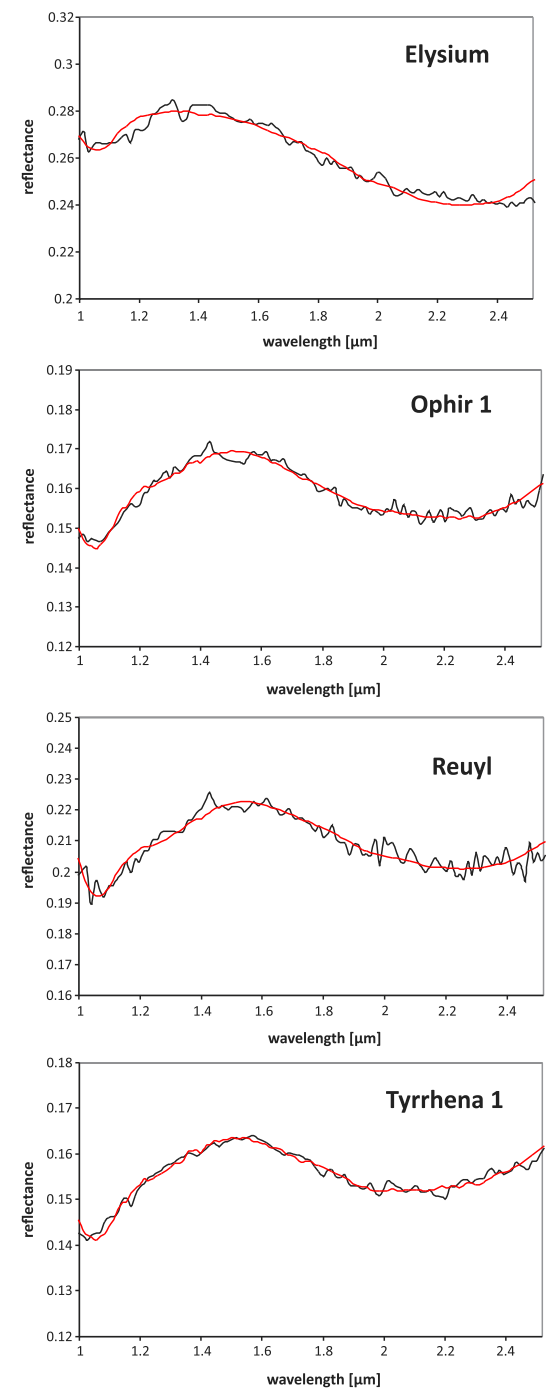
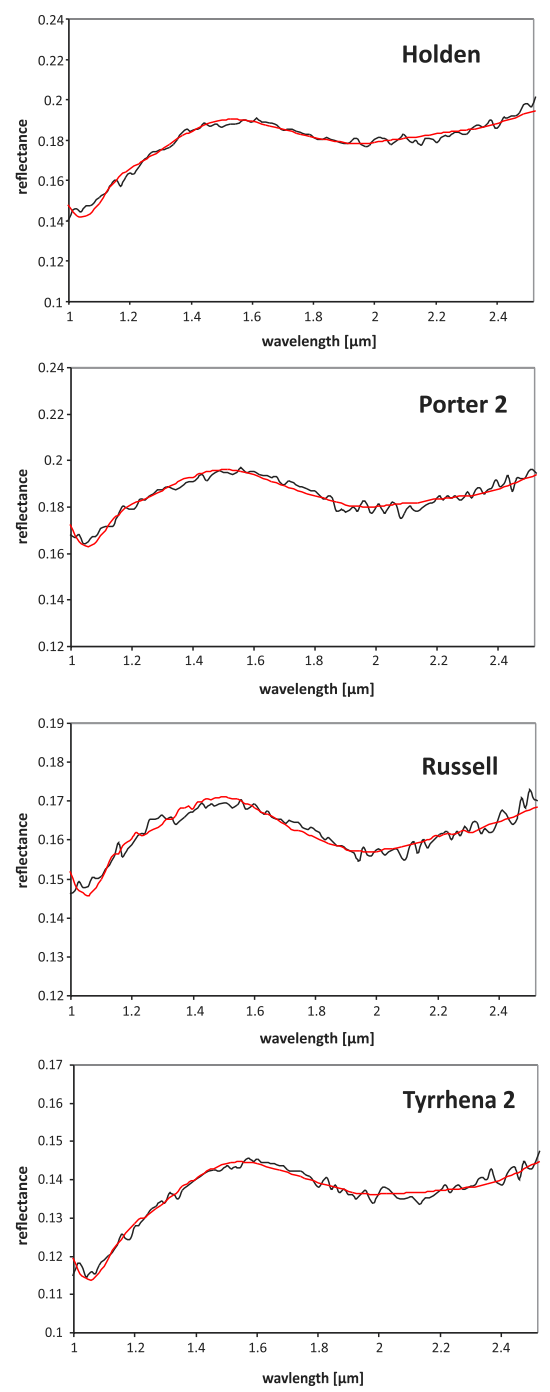

Figure 13. Spectra of dark deposits selected for modal mineralogy compared to their best fit model (black line, data; red line, model). The RMS values range between 0.10 and 0.31 depending on the spectra.

confirmed. This is consistent with the findings of many authors [e.g., Bandfield, 2000, 2002; Bibring et al., 2005, 2006; Christensen et al., 2000; Christensen, 2003; Erard et al., 2004; Poulet et al., 2007; Wyatt et al., 2001; Wyatt and McSween, 2002]. The detection of hydrated minerals, however, shows certain clusters in northern Arabia Terra and Meridiani Planum (Figure 12a). For instance, the northern margin of Arabia Terra must have experienced a long history of aquatic processes, as evidenced by outflow channels and valley networks such as Mawrth Vallis and Mamers Valles [e.g., Hoke and Hynek, 2009a, 2009b; Hynek and Phillips, 2001a, 2001b; Jaumann, 2003; Loizeau et al., 2007b]. Meridiani Planum is assumed to have experienced significant groundwater upwelling and evaporation [Andrews-Hanna et al., 2007a]. The waterrelated processes in these regions are supposed to have resulted in the formation of various minerals, such as phyllosilicates, sulfates, and hematite [e.g., Hynek et al., 2002; Loizeau et al., 2007b; Poulet et al., 2008]. Thus, the detection of hydrated minerals in these regions seems to be associated with the geographical location. Because the aquatic processes and the occurrence of chemically unaltered dark material may not cover the same time scale, it is likely that the detected hydrated spectral signatures are associated more with eroded older terrain material than with dark dune material. Moreover, the dark sediment is unoxidized and might thus be younger than the hydrated material. Alternative effects of a later local alteration of dark material, as discussed above, cannot be ruled out. The diagram in Figure $12 \mathrm{~b}$ presents the statistics of the mineralogical analysis, quoting the detection incidence of each mineral in absolute figures.

[30] The results of the modal mineralogy calculation of 12 selected dark dune fields is shown in Table 2 and Figure 13 (compare Figure 12a for locations). The criteria for the selection of the exemplary locations are quality of the spectra and uniform distribution on the surface of Mars in order to provide random sample information for all geo- 
Table 2. OMEGA Derived Modal Mineralogy of Selected Dark Sediment Deposits

\begin{tabular}{|c|c|c|c|c|c|c|c|c|}
\hline Locality ID & Latitude $\left({ }^{\circ} \mathrm{N}\right)$ & Longitude $\left({ }^{\circ} \mathrm{E}\right)$ & $\mathrm{HCP}^{\mathrm{a}}$ & $\mathrm{LCP}^{\mathrm{a}}$ & Olivine $^{\mathrm{a}}$ & Plagioclase $^{\mathrm{a}}$ & Dust $^{\mathrm{a}}$ & RMS \\
\hline Chaos 4 & 8.3542 & 344.2412 & 20 & 7 & 10 & 34 & 28 & 0.24 \\
\hline Elysium & 9.5342 & 150.267 & 24 & 7 & $<5$ & 41 & 25 & 0.31 \\
\hline Holden & -25.9309 & 326.1140 & 21 & 16 & 19 & 40 & 4 & 0.21 \\
\hline Moreux & 41.3477 & 44.5735 & 25 & 10 & 7 & 55 & 3 & 0.15 \\
\hline Ophir 1 & -3.3860 & 307.6107 & 23 & 9 & 8 & 55 & 5 & 0.15 \\
\hline Porter 2 & -52.8040 & 246.1833 & 22 & 12 & 16 & 40 & 10 & 0.20 \\
\hline Rabe & -43.6378 & 34.4242 & 25 & 12 & 13 & 45 & 4 & 0.18 \\
\hline Reuyl & -9.8950 & 166.6393 & 22 & 5 & 17 & 45 & 11 & 0.27 \\
\hline Russell & -54.6009 & 12.4200 & 20 & 14 & 10 & 51 & 5 & 0.18 \\
\hline Sirenum 1 & -35.3054 & 195.3096 & 25 & 7 & 7 & 55 & 6 & 0.17 \\
\hline Tyrrhena 1 & -14.5987 & 95.7560 & 17 & 7 & 10 & 56 & 10 & 0.10 \\
\hline Tyrrhena 2 & -13.8044 & 95.4158 & 18 & 12 & 13 & 52 & 5 & 0.13 \\
\hline
\end{tabular}

${ }^{\mathrm{a}}$ Values are in percent $( \pm 5 \%)$. Values for olivine range $\pm 10 \%$. See Figure 13 for spectra and Figure $12 \mathrm{a}$ for locations.

graphic regions. The values shown in Table 2 are relative abundances consisting of measurable (HCP, LCP, and olivine) and assumed material components (plagioclase and dust). Following the model results all examined dark deposits are mostly composed of plagioclase and HCP, followed by LCP, olivine, and dust. Note that for all deposits olivine is required for best fit, even for these locations where olivine could not be detected by the method of mineral detection described before. The variance of the minerals is $8 \%$ for HCP, $11 \%$ for LCP, $14 \%$ for olivine, and $22 \%$ for plagioclase, which is slightly above the error bar limits of the technique. However, the bulk composition is uniform. The differences in mineral concentration are probably attributed to fractionation during particle transport in the atmosphere, different transport distances, and redeposition on the ground. It would be unlikely to have unique percentages of each mineral in every of the globally distributed deposits.

[31] The modal mineralogy of examined deposits is roughly consistent with that inferred from modelings of low-albedo basaltic regions in terms of $\mathrm{HCP}(20 \% \pm 5)$, LCP $(10 \% \pm 5)$ and plagioclase abundances $(50 \% \pm 10)$ [Poulet et al., 2009b]. The most striking difference with typical low-albedo basaltic regions is the abundance of olivine of $10-20 \%$ which is systematically larger than the detection limit of $5-10 \%$ for a grain size of $100 \mu \mathrm{m}$. Modeling without olivine as end-member gives larger Residual Mean Squared (RMS) which reinforces the presence of olivine in these deposits. The enrichment of olivine of about $10-15 \%$ found in the dark dunes in comparison to typical basaltic olivine-poor Martian regions can result from mechanical segregation by aeolian sorting. Such a segregation of olivine grains has been recently reported in volcanic sands in Iceland [Mangold et al., 2010b]. Alternatively, the presence of olivine could indicate that the deposits are relatively recent and did not undergo chemical weathering that preferentially alter olivine. The weathered coating would indeed mask the olivine signature in the NIR wavelength range.

[32] The results show that the dark sediments in the analyzed depressions are of a similar mafic mineralogy. The material composition does not change significantly with geographic or topographic position on Mars. Thus, it can be supposed that the unoxidized dark aeolian sediments in Martian craters might have the same origin and did not experience contact to liquid water or other oxidizing agents.

\section{Discussion}

\subsection{Local Sources of Dark Material}

[33] Morphological conditions show that the material is distributed almost all over Mars. This is barely indicative because the material is obviously distributed by globally acting aeolian processes. The bulk of the Martian crust is composed of basalt, which could be a general source for the mafic sediments. So far, no obvious geologic unit can be distinguished as the source of the dark sediments (except for the dark deposits of the north polar region, which probably have their local origin in the "Planum Boreum Cavi Unit" [Tanaka et al., 2008]). Although the dark sediment is predominantly found on impact crater floors, there is no convincing evidence that it is predominantly blown into the craters. This suggests that the occurrence of such material in the craters might be directly associated with the craters themselves. Morphological analyses of the impact crater rims revealed dark layers exposed in the walls and evidence a transport of the dark layer material into the craters (section 5). Further probable sources of dark sediments could be identified beneath the floors of some craters in eastern Arabia Terra for example. Dark layers might be located just beneath the crater floors and were cut by smaller craters superimposed onto the larger crater floors (see section 5 and Figure 4).

[34] Analyses of image data suggest that there are different ways in which dark layers can be cut by impact craters (Figure 14). In case $\mathrm{A}$, the layer is cut through by larger impacts reaching deeper than the level of the dark layer, so that it is exposed in the crater rim (see Figure 5). In case B, the large impact does not reach the dark layer. However, subsequent smaller impacts that hit the crater floor, reach greater depths, and cut the dark layer in many confined places (see Figure 4).

[35] However, because there is no evidence for the existence of these proposed in situ layers (cases A and B in Figure 14) it cannot be ruled out that the material emerging from crater floors was blown into the crater after the impact, deposited on the crater floor, and subsequently covered by regolith (case $\mathrm{C}$ in Figure 14). Impacts can initiate hydrothermal activity if they hit water or ice-rich target material [Abramov and Kring, 2005; Abramov, 2009] causing min- 

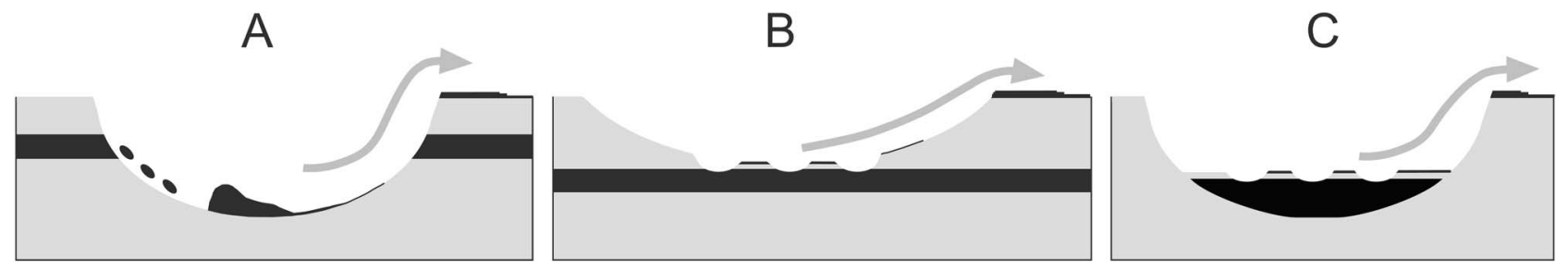

Figure 14. Sketch of possible cases of exposure of dark sediment (see text for discussion).

eralogical and morphological alteration of the crater floor material. Thus, a dark sediment layer located at such a locality would experience hydrothermal alteration. An argument for the dark crater fill approach (case C) is that the material emerging from the crater floors is unweathered and shows no indication of alteration. If hydrothermal activity has taken place, the material must have been deposited on the crater floor after the decline of these processes. However, we did not find any indication for primordial aeolian transport of dark material into craters (e.g., wind streaks), which weakens the argument for case C. In all cases, mechanical erosion of the dark layers seems to result in a supply of fine-grained intracrater material. Gravitational transport downwall and aeolian transport out of the smaller and larger craters provide the local material distribution.

[36] The similarity of exposition of dark layers in the sunfacing wall is remarkable, leading to the assumption that there may be a certain connection between exposure to the sun and the occurrence of these features. In all examples, the opposite pole-facing walls do not show any evidence of dark sediment emersion. This situation suggests that the exposure of the dark layers in crater walls might be associated with the removal of covering dust supported by action of insolation (Figure 15). We suggest that the bright oxidized dust covering craters walls could be (now or in the past) cemented by a very small amount of ice, and that periodically the warming action of solar radiation leads to the sublimation or melting of ice crystals, leaving the bright dust as a loose material. Then, once the underlying dark layers are exposed, processes of thermoclastism took place, favored by the low albedo of such material, and leading to the erosion of dark sediment due to gravitational and/or aeolian processes. Furthermore, once the dark layers are exposed, the continuing (or periodic) erosion of dark materials, inhibit the accumulation of bright dust, leaving the dark material visible in Martian images. This could also explain why dark layers are not observable in all analyzed craters. The dark layers in the crater walls could be covered by weathered regolith or dust, and are exposed only if insolation effects support the removal of the covering layer (Figure 16).

\subsection{Possible Scenarios of Origin}

[37] On Earth, mafic minerals as detected by spectroscopic analyses usually develop as a result of volcanic activity [Markl, 2004; Matthes, 2001]. Analogously, the mafic material on Mars should be of magmatic origin [e.g., Edgett and Lancaster, 1993; Edgett and Christensen, 1994; Fenton and Bandfield, 2003; Fenton, 2005a; Hayward et al., 2007b; Rogers and Christensen, 2003; Ruff and Christensen, 2002]. Thus, the dark deposits might have their origin in the deposition of a thick layer of volcanic ash after volcanic eruptions.

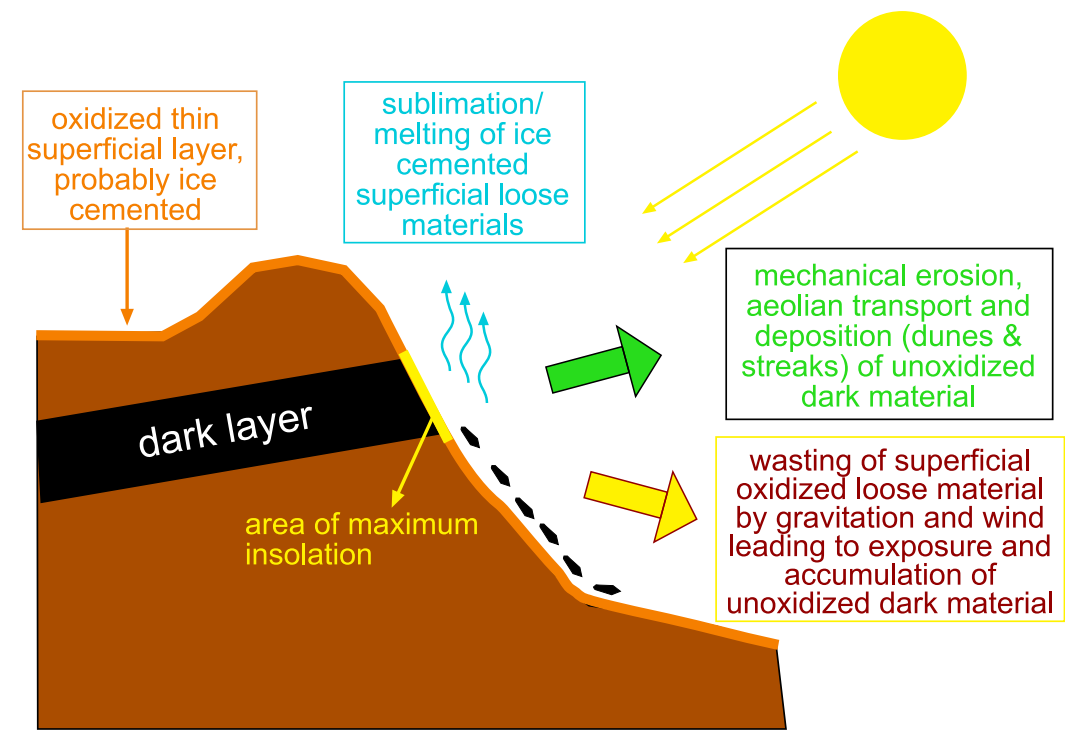

Figure 15. Function diagram of probable processes leading to the exposure of dark layers in crater walls. 


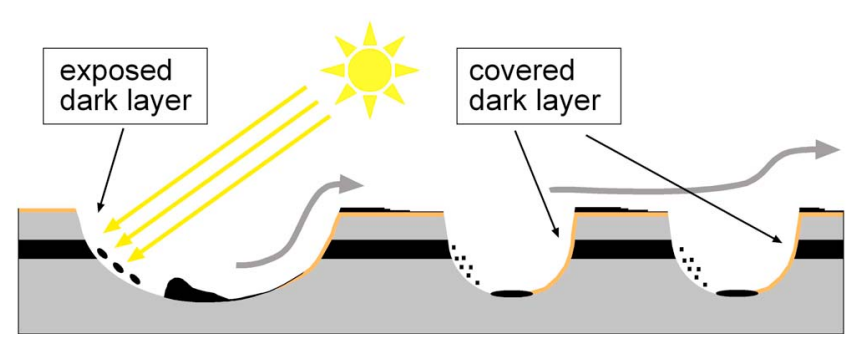

Figure 16. Sketch of probable situations of coverage and exposure of dark layers in crater walls. In the sun-averted wall, any dark layers are covered by regolith or dust (right). Increased solar irradiation of the opposite wall triggers melting and/or erosion and removal of the superficial material mantling the surface (left).

Furthermore, the mechanical disintegration of the upper layer of the basaltic lava (e.g., by insolation weathering which only effects the upper centimeters to decimeters [e.g., Jacobshagen et al., 2000]) might also be seen as an additional source process for the dark layers [Edgett and Lancaster, 1993; Greeley and Spudis, 1981].

[38] As shown in Figure 7 the layers were found in different elevations. Locally these elevation differences can be explained by a dipping of the layers, e.g., due to tectonism (see section 5). Regionally to globally, such elevation differences can also be caused by different elevation of different layers. Thus, the hypothetic volcanic eruptions require the deposition of several different ash layers that are located at different depths in order to explain the observations.

[39] The mineralogical composition of the dark aeolian sediment (pyroxenes and olivines) points to unweathered material which did not undergo chemical alteration and, consequently, did not have contact with liquid water for a relatively long time [Jaumann et al., 2006]. Otherwise, the mafic minerals would have changed into hydrated minerals [Matthes, 2001] which, however, were only found in a few places of Arabia Terra (see section 6). This is another indicator that the material might have been buried and protected during times when liquid water occurred on the Martian surface, otherwise it must be younger.

[40] If the material had its primary genesis in a time before liquid water existed on the surface, this hypothesis would imply that the material is of Early to Mid-Noachian age and was buried from the Middle Noachian to the Late Amazonian period. This age is drawn from the dating of the oldest fluvial events, e.g., the beginning of the formation of extensive valley networks around 4.0 to $3.9 \mathrm{Ga}$ (see Figure 17) [e.g., Carr and Head, 2009; Greeley and Guest, 1987; Jaumann et al., 2009; Marchenko et al., 1998; Masursky et al., 1977; Neukum and Hiller, 1981; Scott and Tanaka, 1986; Werner, 2006]. This scenario of an old age implies an era of genesis approximately between $\sim 4.2$ and 3.9 Ga before present.

[41] Alternatively, the material could be much younger, originating after the wet periods on Mars. This would imply a genesis starting in the Late Amazonian (around 0.1 to $0.05 \mathrm{Ga}$ ), inferred from the age of the youngest fluvial features (see Figure 17) [Head et al., 2001; Jaumann et al., 2009; Werner, 2006]. These two hypotheses of chronological placement are shown in Figure 17, which is derived from Werner [2006], and modified in a way that the two hypothetical epochs when dark material was generated by volcanic activity are added in the form of black bars. The early and late genesis hypotheses are designated as A and $\mathrm{B}$, respectively.

[42] The approach of an old age (hypothesis A, Early to Mid-Noachian, $\sim 4.2$ and $3.9 \mathrm{Ga}$ ) is strengthened by the fact that global volcanism, especially the widespread highland volcanism, had its main activity phase producing high amounts of volcanic ash [e.g., Carr, 1973; Greeley and Spudis, 1981; Neukum and Hiller, 1981; Werner, 2006]. The unaltered nature of the sediment requires a fast burial of the layers protecting the material from oxidation and chemical alteration. Such fast burial could have been accomplished by impact ejecta deposition and lava deposition. The intensive volcanic activity and the high lava production rates of the Early Noachian epoch support the theory of an old material age. Furthermore, the high cratering records of this epoch [Hartmann and Neukum, 2001; Neukum and Hiller, 1981] support the fast burial and strengthen the theory as well.

[43] The global distribution of the dark material produced by global volcanism might have been easily accomplished

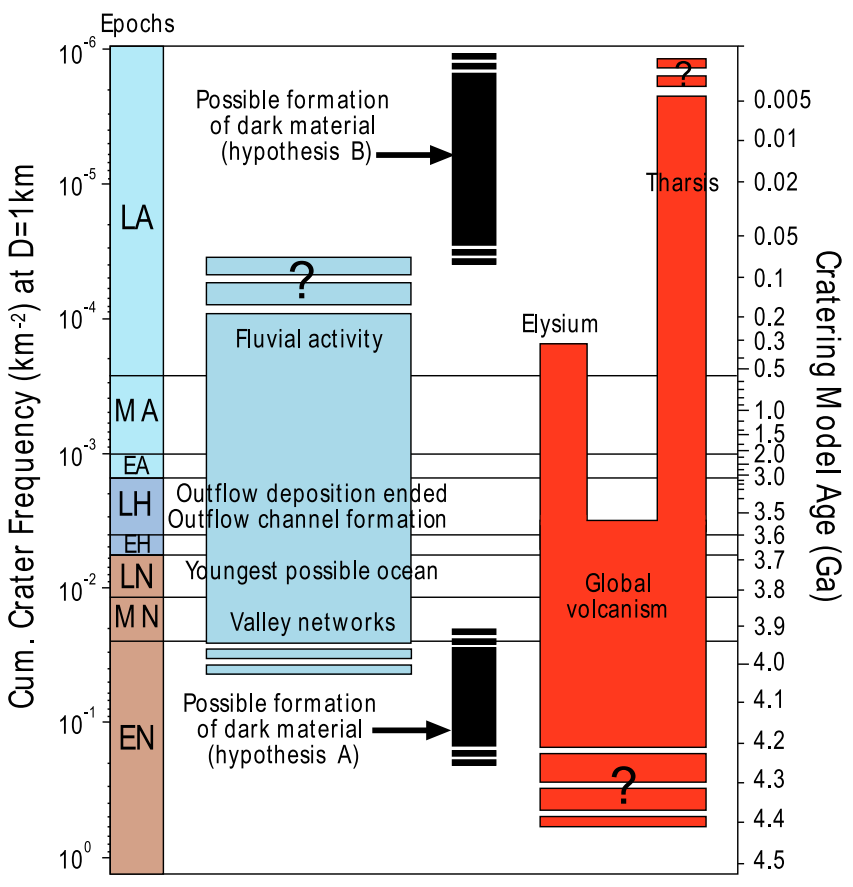

Figure 17. Possible periods of dark material formation incorporated in the sequence of the global geological evolution of Mars (adopted from Werner [2006], modified). The two hypothetical periods for the formation of dark material (hypotheses A and B) following the volcanic ash theory are represented by black bars. Ages were determined by Werner [2006] and are here given in terms of cumulative crater frequency (left axis) and in absolute figures (right axis). Geological epochs are abbreviated as follows: EN, MN, and LN for Early, Middle, and Late Noachian; EH and LH for Early and Late Hesperian; and EA, MA, and LA for Early, Middle, and Late Amazonian (boundaries following Tanaka et al. [1992]). 
because the erupted ash material was thrown to high altitudes in the atmosphere and distributed widely by aeolian processes. In the following epochs (between 3.9 and $0.1 \mathrm{Ga}$ ) intense fluvial processes acted on the Martian surface [e.g., Carr and Head, 2009; Greeley and Guest, 1987; Jaumann et al., 2009; Marchenko et al., 1998; Masursky et al., 1977; Neukum and Hiller, 1981; Scott and Tanaka, 1986; Werner, 2006]. Thus, it is unlikely that the building of the dark material can be set into this time because of its unweathered unoxidized nature.

[44] The approach of a young age (hypothesis B, around 0.1 to $0.005 \mathrm{Ga}$ ) associated with a volcanic origin would imply the building of dark deposits mainly caused by the Tharsis volcanism in the Late Amazonian period after the decline of fluvial activities (see Figure 17). However, the volcanic activity on Mars was less intense and locally restricted to the Tharsis region at that time [Neukum and Hiller, 1981; Neukum et al., 2004b; Werner, 2006]. Thus, it is questionable whether this weak volcanic activity might have produced these ash layers. Furthermore, although the huge Tharsis volcanoes were active until 100,000 years before present [Neukum et al., 2004b] the time since might not be sufficient to deposit the layers and cover them globally with ejecta, lava and regolith. For the covering material at Rabe crater $\left(43.96^{\circ} \mathrm{S}, 34.84^{\circ} \mathrm{E}\right)$, we measured a minimum thickness of about $\sim 60 \mathrm{~m}$ to $115 \mathrm{~m} \pm 67.5 \mathrm{~m}$ (by using HRSC DTMs [Gwinner et al., 2005, 2009a, 2009b]). Erosion rates on Mars show a dramatic drop of 4-6 magnitudes between the Noachian $\left(10^{2}-10^{4} \mathrm{~nm} / \mathrm{a}\right)$ and the Hesperian/Amazonian period $\left(10^{-2}-10^{-1} \mathrm{~nm} / \mathrm{a}\right)$ [Golombek and Bridges, 2000; Golombek et al., 2006]. Calculations of Golombek et al. [2007] result in long-term erosion rates of $0.01-10 \mathrm{~nm} / \mathrm{a}$ since the Hesperian. Low erosion rates imply in turn low sedimentation rates because a small amount of eroded material is produced for sedimentation and accumulation [e.g., Jacobshagen et al., 2000]. Thus, we assume the sedimentation rates to be in the range of the mentioned erosion rates. Even with the highest assumed Hesperian/ Amazonian erosion rates of $10 \mathrm{~nm} / \mathrm{a}$ it would take at least $6 \mathrm{Ga}$ to deposit materials of $60 \mathrm{~m}$ thickness covering the dark layers. Such low erosion rates make it impossible that such a thick layer of deposits should have accumulated above the dark layer in the Late Amazonian period. In turn, the high Noachian erosion rates (e.g., with a rate of $10^{4} \mathrm{~nm} / \mathrm{a}$ it takes only $0.006 \mathrm{Ga}$ to deposit material of $60 \mathrm{~m}$ thickness on the surface) and the intense processes supporting a fast coverage of the dark layers (i.e., ejecta blankets by impact erosion, lava flows by global volcanic activity) support the idea of an old age because the fast burial and coverage of the dark layer seems reasonable.

[45] A further fact weakening hypothesis B (young age) is that the impact craters in which we observed dark layer outcrops along crater walls are quite large and should be at least Hesperian in origin. As a consequence, the material forming dark layers and outcropping at such craters walls should be older than the craters in which they appear. Thus it is unlikely that the material is of Amazonian age. Otherwise, if dark materials are Amazonian in origin and the $\mathrm{B}$ hypothesis is true, only case $\mathrm{C}$ of Figure 14 could be plausible, not cases A or B.

[46] An alternative approach concerning the origin of the dark sediment on Mars was proposed by Schultz and
Mustard [2004] and further investigated by Wrobel and Schultz [2006, 2007]. They propose that the dark sediments on Mars could be the product of well-preserved impact-related materials, i.e., impact glasses or impact melts, accumulated since the Hesperian and generated by the huge number of impact bombardments on Mars. To support this suggestion, they name various indicators: (1) the absence of a mafic spectral signature of certain dark deposits on Mars; (2) the feldspathic composition of several blocks found at the Pathfinder landing site pointing to andesites rather than basalts; (3) indications based on terrestrial analogues in Argentina pointing to the formation of global distal melts caused by impacts into soft loess deposits, which they call the prime terrestrial analogue for Martian sediments; and (4) the possibility of a global dispersal of impact material driven by the Coriolis force, as evidenced by terrestrial observations [Schultz and Mustard, 2004; Wrobel and Schultz, 2004]. Wrobel and Schultz [2007] performed a quantitative study using computer simulations incorporating hydrocode models and ballistic ejecta delivery calculations to predict the distribution of distal impact melts across Mars since post-Noachian times generated by impacts producing $>100 \mathrm{~km}$ diameter craters. They compared the results with an albedo map of Mars [see Wrobel and Schultz, 2007, Figures 2a and 2b] and recognized correlations between areas of extensive impact melt coverage and lowalbedo regions. For example, they identified the huge amounts of dark material depositions at Oxia Palus [see Wrobel and Schultz, 2007, Figure 2c] (previously classified as Surface Type I by Bandfield [2000] and Christensen et al. [2001]) as generated by the massive impact which caused Lyot crater. According to Wrobel and Schultz [2007], parts of the material were transported by aeolian deflation from this source northeast of Oxia Palus to its present-day locations. Furthermore, glasses produced by the Lyot impact were identified as possibly responsible for the dark deposits at Acidalia Planum (classified as Surface Type II by Bandfield [2000] and Christensen et al. [2001]), which have undergone a different history of alteration and aeolian redistribution. The authors found further correlation between predicted impact melt concentrations and low-albedo regions on Mars in the Hesperia Planum region [see Wrobel and Schultz, 2007, Figure 2d] interpreted as mobile glasses weathered out of previously protected sediments [Wrobel and Schultz, 2007].

[47] Regarding the preservation of the material within sediment layers, trapped in and emanating from craters, exhumation, mechanical breakdown, and deflation, the impact glass hypothesis holds views similar to those previously discussed in this work. However, the absence of mafic signatures cannot be confirmed for the dark materials analyzed. Although Schultz and Mustard [2004] cited this fact as an indication of the nonvolcanic origin of the dark sediment, Wrobel and Schultz [2007] later admitted that the mafic composition might be due to the predominantly basaltic source material of the impact melts. One further conspicuous point is the difference between the mapped melt concentrations and the low-albedo regions [see Wrobel and Schultz, 2007, Figures 2a and 2b] although the authors explain these differences by the existence of dust covers, depositional traps in thick sediments, and aeolian redistribution. Dating the genesis of 

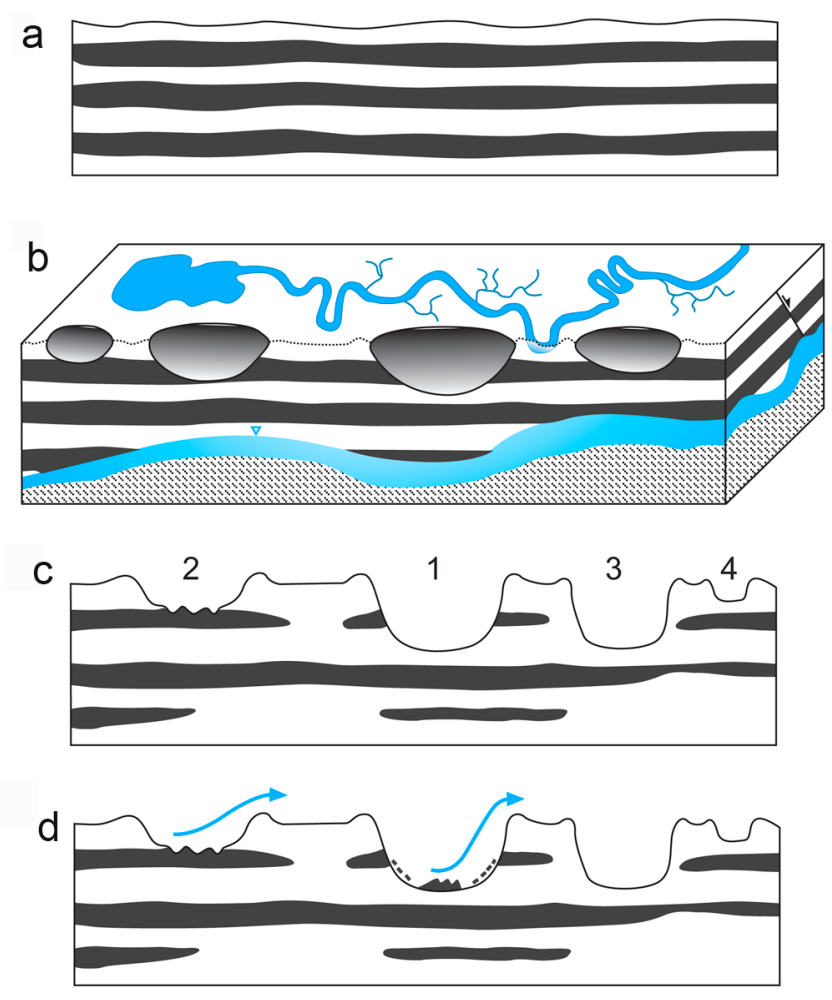

Figure 18. Example of the development of dark layers. (a) Initial state: deposition and burial of dark layers. (b) Modification of dark layers: impacts from above and groundwater from underneath remove and alter the material piecemeal, resulting in highly fragmented layers. Crustal movement, e.g., normal faults, may cause dislocation of the layers. Superficial fluvial processes do not influence protected dark layers. (c) Patchy and fragmented layer distribution: crater-layer relationship has different characteristics: (1) impact crater cuts layer $\Rightarrow$ dark layers exposed in crater wall; (2) smaller craters on the larger crater's floor cut layer $\Rightarrow$ dark sediment emerges from smaller craters onto the larger crater's floor; (3) impact crater of similar depth as the crater of situation 1 , although close to other layer exposure sites, does not cut into a dark layer because dark layers have been removed in that location; (4) impact crater does not reach the dark layer. (d) Final state: mechanical weathering of layer material and aeolian processes result in dune formation on crater floors, building of wind streaks and widespread distribution of dark aeolian sediment.

dark sediments back to Noachian times does not completely exclude the impact glass hypothesis. However, due to the amorphous nature of impact glasses it would not be possible to obtain a mineralogical absorption signature [Pieters, 1977]. It is not until recrystallization takes place that crystal lattice vibrations in mineral grains produce distinct spectral absorption features. From lunar research it is known that volcanic glasses (orange glass) have an age of 3.5 to $3.6 \mathrm{Ga}$ and have not recrystallized until today: only the upper most noncovered "black soil" layer has experienced recrystallization [Stoeffler et al., 2006]. Likewise, lunar impact glasses are $3.5 \mathrm{Ga}$ old and have not undergone any recrystallization [Stoeffler et al., 2006]. This weakens the impact glass hypothesis and strengthens the arguments for the volcanic origin theory because the dark sediment spectrally consists of distinct crystallized mineral grains.

\subsection{Chronology of Evolution}

[48] As discussed above, the origin events (i.e., volcanic eruptions or impacts) caused the deposition of one or more layers of dark sediment. We did not find evidence of multiple layers in crater walls or other sites of exposure yet. However, the existence of several layers cannot be ruled out because the origin events might have gone through several phases with unknown time intervals in between. Of course, if there was only one giant volcanic eruption or impact, only one dark sediment layer should have resulted. However, craters with emanating dark sediments are situated close to craters without dark material in some regions (see Figure 4), pointing to the fact that the layers of dark sediment are not continuous and are of different elevations. Furthermore, the individual layers might vary in thickness. The following interpretation describes the evolution of dark material as postulated in hypothesis A described in section 5 (see Figure 17).

[49] After deposition and burial (Figure 18a), the layers might have been modified in different ways (Figure 18b). Impact craters have cut through the upper layers, removing a given amount of material each time. The impact-removed material was ejected to the surrounding surface and exposed to weathering, probably leading to chemical alteration and/ or oxidation of the material. This ongoing processes resulted in the fragmentation of the upper layer, probably removing the material completely in many places. In some regions, crustal movement, such as normal or reverse faults or dipping, might have shifted the layers deeper or higher. Furthermore, large- and small-scale erosional events (such the development of the outflow channels [e.g., Carr and Clow, 1981; Carr and Malin, 2000; Jaumann, 2003; Komar, 1980; Lanz, 2004; Nelson and Greeley, 1999]) might have completely removed large amounts of the material in certain regions. Water welling up from beneath the surface (especially in the Meridiani Planum region) [Andrews-Hanna et al., 2007a, 2007b] might have reached the lower layers, so that the material was chemically altered and washed out. Consequently, the lower layers might be extremely fragmented as well. During the wet periods on Mars (Late Noachian until the first half Late Amazonian), the buried material was, if it already existed, protected from superficial fluvial processes. Thus, dark sediment layers were not exposed to superficial chemical weathering, resulting in the unaltered condition of the material today. Although huge amounts of the originally deposited sediments were removed or altered by erosional and weathering processes, large amounts of dark material deposited in fragmented and locally restricted layers still exist on Mars. Some of the layers are probably nothing more than small lenses or elongated patches. Extensive modification, displacement, and removal of these layers explain regional variations in the occurrence and exposure of dark sediment. There are different types of layer exposure in Martian craters: First, in places where an impact crater cuts through a dark layer deeper than its bottom, the layer will be exposed in the crater wall (situation 1, Figure 18c). As discussed in 
section 5 , these exposures might be coated by regolith or dust covering the crater wall, whereas insolation effects probably support the exhumation and mobilization of coated dark layers. Second, some impact craters might come close to but not completely reach the depth of the dark layers. Subsequent smaller impacts on the same crater floor might cut into the dark layers lying just beneath the larger crater's floor, exposing the dark material in this second step (situation 2, Figure 18c). Third, craters located close to other impacts where dark materials have been exposed may not cut into a dark layer because the dark material was removed from this locality or displaced to greater depths, the impact thus hit a gap in the dark layer (situation 3, Figure 18c). Therefore, these craters do not show any indication of dark sediment although they are situated in a potential region for dark layer exposure (see profile in Figure 4, section 5). Fourth, the crater depth does not reach the depth of the dark layer (situation 4, Figure 18c).

[50] The material will be transported from the walls into the crater's interior, where it forms dunes, dune fields, or sand sheets. Evidence for such sediment transport can be seen in gullies filled with dark material that run downwall below exposed dark layers (see Figures 5c and 5d and section 5). Furthermore, intracrater material can be blown out of the craters by wind action. Downwind of these craters, dark wind streaks develop from deflated dune material. Material emerging from dark layers (situation 1 and 2, Figure 18c), its mobilization, and the formation of dunes and wind streaks is illustrated in Figure $18 \mathrm{~d}$. Most of the dark dunes seem not to migrate or shift very much [e.g., Breed et al., 1979; Edgett, 2002; Malin and Edgett, 2001; Schatz et al., 2006; Tirsch et al., 2007; Zimbelman, 2000] and observations of moving or disappearing dunes are rare [e.g., Bourke and Edgett, 2006; Bourke et al., 2008; Fenton, 2005b; Silvestro et al., 2010]. At the same time, the size of several dune fields indicates great age, and the physical conditions for sand particle movement on Mars [e.g., Edgett and Christensen, 1991; Greeley and Iversen, 1985; Iversen and White, 1982] support the concept of old stable dune bodies [cf. Tirsch, 2009].

\section{Conclusion}

[51] Referring to the detailed analyses we can conclude the following facts:

[52] 1. The dark aeolian sediments have not primarily been blown into the craters, as formerly assumed by many authors [e.g., Edgett and Malin, 2000; Greeley et al., 1993; Jaumann et al., 2006; Malin and Edgett, 2001] but seems to originate in the craters themselves. The lack of convincing evidence of distinct material input into the craters and many examples of dark sediment emerging out from craters support this interpretation.

[53] 2. Dark layers exposed in the crater walls and beneath some crater floors are most likely the local source of dark intracrater aeolian deposits. Obvious sediment transport pathways from the source layer to the dunes and a mineralogical composition similar to the intracrater dune material corroborate this conclusion.

[54] 3. Insolation seems to be the mechanism supporting layer exposure in crater walls if they are covered by regolith.
[55] 4. The compositional mixture of unweathered pyroxenes and olivines formerly assumed by many authors [e.g., Christensen et al., 2000; Bandfield, 2002; Bibring and Erard, 2001; Bibring et al., 2006; Hoefen et al., 2003; Mangold et al., 2007; Mustard et al., 2005, 2007] was confirmed by detailed spectral analysis. The mineralogical composition of the bulk of the dark dunes and sand sheets is consistent and shows no variation within the geographical locations in terms of mafic minerals. However, hydrated minerals detected in small parts of some dark deposits form clusters in Arabia Terra. This is interpreted to be due to the former activity of waterrelated processes in this particular region.

[56] 5. The detection of olivine in the dark sediments emerging from the layers exposed in the crater walls indicates a low level of weathering and thus relatively fresh sediment.

[57] The generally consistent mafic composition of dark sediments without any geographical control points to a similar origin of all dark deposits. Thus, the dark material was probably developed during similar formation processes with a regional or global reach. Indications of the nature of this formation process came from the mineralogical composition. Olivine and pyroxene minerals, detected as the major components of the dark sediments, might be indicative of a volcanic origin. Furthermore, these minerals must have been protected during times of active fluvial processes on Mars; otherwise, they would have been altered by chemical weathering. Morphological aspects of the dark layers found in several craters disclose that they were buried after deposition and later exposed by impact erosion. The layered nature of the sediment and its mineralogical composition strengthens the concept that it was generated by time-restricted events, such as volcanic eruptions leading to the deposition of thick ash layers. The geological history of Mars suggests a time range of genesis from the Early to the Middle Noachian period ( 4.2 to $3.9 \mathrm{Ga})$, when global volcanism reached its peak, and widespread fluvial processes just began to act. It is plausible that the sediment was deposited and subsequently buried during this time and fluvial processes did not alter or clear out the buried dark layers completely.

[58] Based on the morphological characteristics of the dark layers, it can be assumed that the sediments have to be generated by several events rather than by a single one. Consequently, it cannot be ruled out that several layers of dark material produced by several periodic events exist beneath the surface of Mars, although we did not find any image evidence yet. The picture of the evolution of the dark sediment after its genesis is less blurred after this analysis. As shown in Figure 18, layers might have experienced several stages of modification after their deposition and burial. Related factors include impact erosion of the upper layers, chemical alteration by groundwater from beneath, and probably displacement of layers by tectonic processes, resulting in a highly fragmented nature of each layer. Evidence of this layer fragmentation might be provided by the various cases of layer exposure. The last stage of layer development is clearly inferable from the current material appearance on Mars. Mechanical weathering of dark material sources provides sediments for intracrater dunes and sand sheets of various types and sizes. These aeolian bed 
forms frequently experience deflation by wind, thus forming the source of the dark crater-related wind streaks on Mars.

[59] Acknowledgments. This research has been supported by the Helmholtz Association through the research alliance "Planetary Evolution and Life." We thank the HRSC and OMEGA Experiment teams at DLR Berlin, Freie Universitaet Berlin, and the Institut d'Astrophysique Spatiale Orsay as well as the Mars Express Project teams at ESTEC and ESOC for their successful planning and acquisition of data as well as for making the processed data available to the HRSC team. We acknowledge the detailed reviews of David A. Williams, Mariam Sowe, and one anonymous reviewer that significantly improved this paper.

\section{References}

Abramov, O. (2009), Modeling hydrothermal activity associated with Martian impact craters: An overview, LPI Contrib., 1482, 9-10.

Abramov, O., and D. Kring (2005), Impact-induced hydrothermal activity on early Mars, J. Geophys. Res., 110, E12S09, doi:10.1029/ 2005JE002453.

Adams, J. (1975), Interpretation of visible and near-infrared diffuse reflectence spectra of pyroxenes and other rock-forming minerals, in Infrared and Raman Spectroscopy of Lunar and Terrestrial Minerals, edited by C. Karr Jr., pp. 91-116, Academic, New York.

Andrews-Hanna, J. C., R. J. Phillips, and M. T. Zuber (2007a), Meridiani Planum and the global hydrology of Mars, Nature, 446, 163-166, doi:10.1038/nature 05594

Andrews-Hanna, J. C., M. T. Zuber, and R. J. Phillips (2007b), Meridiani Planum: Implications for the hydrologic and climatic evolution of Mars, in Seventh International Conference on Mars, July 9-13, 2007, Pasadena CA [CD-ROM], LPI Contrib., 1353, Abstract 3173.

Arvidson, R. (1974), Windblown streaks, splotches, and associated craters on Mars: Statistical analysis of Mariner 9 photographs, Icarus, 21 $12-27$

Arvidson, R., et al. (2005), Spectral reflectance and morphologic correlations in eastern Terra Meridiani, Mars, Science, 307, 1591-1594.

Bandfield, J. (2000), A global view of Martian surface compositions from MGS-TES, Science, 287, 1626-1630.

Bandfield, J. (2002), Global mineral distributions on Mars, J. Geophys. Res., 107(E6), 5042, doi:10.1029/2001JE001510.

Bell, P., H. Mao, and G. Rossman (1975), Absorption spectroscopy of ionic and molecular units in crystals and glasses, in Infrared and Raman Spectroscpy of Lunar and Terrestrial Minerals, edited by C. Karr Jr., pp. 1-38, Academic, New York.

Bellucci, G., F. Altieri, J.-P. Bibring, G. Bonello, Y. Langevin, B. Gondet and F. Poulet (2006), OMEGA/Mars Express: Visual channel performances and data reduction techniques, Planet. Space Sci., 54, 675-684

Bibring, J.-P., and S. Erard (2001), The Martian surface composition, Space Sci. Rev., 96, 293-316.

Bibring, J. P., et al. (2004), OMEGA: Observatoire pour la Minéralogie, l'Eau, les Glaces et l'Activité, ESA Spec. Publ., ESA-SP 1240, 37-49.

Bibring, J.-P., et al. (2005), Mars surface diversity as revealed by the OMEGA/Mars Express observations, Science, 307, 1576-1581, doi: $10.1126 /$ science. 1108806 .

Bibring, J.-P., et al. (2006), Global mineralogical and aqueous Mars history derived from OMEGA/Mars Express data, Science, 312, 400-404.

Bishop, J., et al. (2008a), Phyllosilicate diversity and past aqueous activity revealed at Mawrth Vallis, Mars, Science, 321, 830-833.

Bishop, J. L., N. K. McKeown, E. Z. Noe Dobrea, S. L. Murchie, and J. F. Mustard (2008b), Aqueous processes and active chemistry inferred from phyllosilicate record at Mawrth Vallis, Mars, LPI Contrib., 1441, pp. 19-20.

Bonello, G., J.-P. Bibring, F. Poulet, A. Gendrin, B. Gondet, Y. Langevin and S. Fonti (2004), Visible and infrared spectroscopy of minerals and mixtures with the OMEGA/Mars-Express instrument, Planet. Space Sci., 52, 133-140.

Bourke, M. C. (2005), Alluvial fans on dunes in Kaiser crater suggest niveo-aeolian and denivation processes on Mars, Lunar Planet. Sci. $X X X V I$, Abstract 2373

Bourke, M. C., and K. S. Edgett (2006), First evidence of dune movement on Mars, Eos Trans. AGU, 87(52), Fall Meet. Suppl., Abstract P31B-0128.

Bourke, M., K. Edgett, and B. Cantor (2008), Recent eolian dune change on Mars, Geomorphology, 94(1-2), 247-255.

Breed, C. S. (1977), Terrestrial analogs of the hellespontus dunes, Mars, Icarus, 30, 326-340.
Breed, C. S., M. J. Grolier, and J. F. McCauley (1979), Morphology and distribution of common "sand" dunes on Mars: Comparison with the Earth, J. Geophys. Res., 84, 8183-8204

Burns, R. (1970), Mineralogical Application of Crystal Field Theory, Cambridge Univ. Press, Cambridge, U. K

Carr, M. H. (1973), Volcanism on Mars, J. Geophys. Res., 78, 4049-4062.

Carr, M. H., and G. D. Clow (1981), Martian channels and valleys: Their characteristics, distribution, and age, Icarus, 48, 91-117, doi:10.1016/ 0019-1035(81)90156-1.

Carr, M., and J. W. Head (2009), Geologic history of Mars, Earth Planet. Sci. Lett., 294, 185-203, doi:10.1016/j.eps1.2009.06.042.

Carr, M., and M. Malin (2000), Meter-scale characteristics of Martian channels and valleys, Icarus, 146, 366-386, doi:10.1006/icar.2000.6428.

Chapman, M. G., A. Dumke, G. Michaels, and G. Neukum (2007), Possible glacial erosion of interior layered deposit mounds in central Candor Chasma, Eos Trans. AGU, 88(52), Fall Meet. Suppl., Abstract P31C-0547.

Christensen, P. (1983), Eolian intracrater deposits on Mars: Physical properties and global distribution, Icarus, 56, 496-518.

Christensen, P. (2003), Formation of recent Martian gullies through melting of extensive water-rich snow deposits, Nature, 422, 45-48.

Christensen, P., et al. (1998), Results from the Mars Global Surveyor Thermal Emission Imaging Spectrometer, Science, 279, 1692-1698.

Christensen, P., J. Bandfield, D. E. Smith, V. Hamilton, and R. Clark (2000), Identification of a basaltic component on the Martian surface from Thermal Emission Spectrometer data, J. Geophys. Res., 105, 9609-9621.

Christensen, P., et al. (2001), Mars Global Surveyor Thermal Emission Spectrometer experiment: Investigation description and surface science results, J. Geophys. Res., 106, 23,823-23,871.

Christensen, P., et al. (2003), Morphology and composition of the surface of Mars: Mars Odyssey THEMIS results, Science, 300, 2056-2061.

Christensen, P., et al. (2004), Mineralogy at Meridiani Planum from the Mini-TES experiment on the opportunity rover, Science, 306, 1733-1739.

Deer, W., R. Howie, and J. Zussman (1963), Rock-Forming Minerals, vol. 3, Sheet Silicates, Longman, Essex, U. K.

Edgett, K. S. (2002), Low-albedo surfaces and eolian sediment: Mars orbiter camera views of western Arabia Terra craters and wind streaks, J. Geophys. Res., 107(E6), 5038, doi:10.1029/2001JE001587.

Edgett, K., and D. Blumberg (1994), Star and linear dunes on Mars, Icarus, 112, 448-464, doi:10.1006/icar.1994.1197.

Edgett, K., and P. R. Christensen (1991), The particle size of Martian aeolian dunes, J. Geophys. Res., 96, 22,762-22,776.

Edgett, K., and P. R. Christensen (1994), Mars aeolian sand: Regional variations among dark-hued crater floor features, J. Geophys. Res., 99 1997-2018.

Edgett, K., and N. Lancaster (1993), Volcaniclastic aeolian dunes: Terrestrial examples and application to Martian sands, J. Arid Environ., 25, 271-297.

Edgett, K., and M. C. Malin (2000), New views of Mars eolian activity, materials, and surface properties: Three vignettes from the Mars Global Surveyor Mars Orbiter Camera, J. Geophys. Res., 105, 1623-1650.

Erard, S., Y. Langevin, O. Forni, F. Poulet, and J. P. Bibring (2004), Olivine-rich patches observed by OMEGA, paper presented at 35 th Scientific Assembly, p. 3989, Comm. on Space Res., Paris.

Fenton, L. (2005a), Potential sand sources for the dune fields in Noachis Terra, Mars, J. Geophys. Res., 110, E11004, doi:10.1029/2005JE002436.

Fenton, L. (2005b), Seasonal movement of material on dunes in proctor crater, Mars: Possible present-day sand saltation, Lunar Planet. Sci. $X X X V I$, Abstract 2169

Fenton, L. (2006), Dune migration and slip face advancement in Rabe crater dune field, Mars, Geophys. Res. Lett., 33, L20201, doi:10.1029/ 2006GL027133.

Fenton, L. (2008), Gullies as a source of aeolian sand in the southern midlatitudes, LPI Contrib., 1303, 36-37.

Fenton, L., and J. Bandfield (2003), Aeolian processes in Proctor crater on Mars: Sedimentary history as analyzed from multiple data sets, J. Geophys. Res., 108(E12), 5129, doi:10.1029/2002JE002015.

Fenton, L., and R. Hayward (2008), Southern hemisphere dunes of Mars: Morphology trends and climate change, LPI Contrib., 1403, 35-36.

Fenton, L., and M. Mellon (2006), Thermal properties of sand from Thermal Emission Imaging Spectrometer (TES) and Thermal Emission Imaging System (THEMIS): Spatial variations within the Proctor crater dune field on Mars, J. Geophys. Res., 111, E06014, doi:10.1029/2004JE002363.

Fenton, L. K., R. K. Hayward, K. F. Mullins, T. N. Titus, and T. Colaprete (2007), Mars digital dune database: More preliminary science results, Lunar Planet. Sci., XXXVIII, Abstract 1486

Forni, O., F. Poulet, J.-P. Bibring, S. Erard, C. Gomez, Y. Langevin, B. Gondet, and T. O. S. Team (2005), Component separation of OMEGA spectra with ica, Lunar Planet. Sci., XXXVI, Abstract 1623 
Fueten, F., R. M. Stesky, and P. MacKinnon (2005), Structural attitudes of large-scale layering in Valles Marineris, Mars, calculated from Mars Orbiter Laser Altimeter data and Mars Orbiter Camera imagery, Icarus, $175,68-77$

Gendrin, A. (2005), Sulfates in the Martian layered terrains: The OMEGA/ Mars Express view, Science, 307, 1587-1591.

Golombek, M. P., and N. Bridges (2000), Erosion rates on Mars and implication for climate change: Constraints from pathfinder landing site J. Geophys. Res., 105, 1841-1853.

Golombek, M. P., et al. (2006), Erosion rates at the Mars Exploration Rover landing sites and long-term climate change on Mars, J. Geophys. Res. 111, E12S10, doi:10.1029/2006JE002754.

Golombek, M. P., et al. (2007), Climate change on Mars from erosion rates at the Mars exploration rover landing sites, in Seventh International Conference on Mars, July 9-13, 2007, Pasadena CA [CD-ROM], LPI Contrib., 1353, Abstract 3034.

Greeley, R., and J. Guest (1987), Geological map of the eastern equatorial region of Mars, U.S. Geol. Surv. Misc. Invest. Map I-1802-B, $1: 15,000,000$

Greeley, R., and J. Iversen (1985), Wind As a Geological Process on Earth, Mars, Venus and Titan, Cambridge Univ. Press, New York.

Greeley, R., and P. D. Spudis (1981), Volcanism on Mars, Rev. Geophys. 19, $13-41$.

Greeley, R., N. Lancaster, S. Lee, and P. Thomas (1992), Martian aeolian processes, sediments and features, in Mars, edited by H. Kieffer et al., pp. 730-766, Univ. of Ariz. Press, Tucson.

Greeley, R., A. Skypeck, and J. Pollack (1993), Martian aeolian features and deposits: Comparisons with general circulation model results, J. Geophys. Res., 98, 3183-3196.

Greeley, R., M. Kraft, R. Sullivan, G. Wilson, N. Bridges, K. Herkenhoff, R. O. Kuzmin, M. Malin, and W. Ward (1999), Aeolian features and processes at the Mars pathfinder landing site, J. Geophys. Res., 104, 8573-8584, doi:10.1029/98JE02553.

Grégoire, M., D. Baratoux, N. Mangold, O. Arnalds, B. Platvoet J. Bardinzeff, and P. Pinet (2007), Which processes form the volcanic sands on Mars?, Eos Trans. $A G U, 88(52)$, Fall Meet. Suppl., Abstract P31C-0551.

Gwinner, K., F. Scholten, B. Giese, J. Oberst, R. Jaumann, M. Spiegel, R. Schmidt, and G. Neukum (2005), Hochaufloesende Gelaendemodelle auf der Grundlage von Mars Express HRSC-Daten, Photogramm Fernerkundung Geoinf., 5, 387-394.

Gwinner, K., F. Scholten, M. Spiegel, R. Schmidt, B. Giese, J. Oberst C. Heipke, R. Jaumann, and G. Neukum (2009a), Derivation and validation of high-resolution digital terrain models from Mars Express HRSC data, Photogramm. Eng. Remote Sens., 75(9), 1127-1142.

Gwinner, K., et al. (2009b), Topography of Mars from global mapping by HRSC high-resolution digital terrain 2 models and orthoimages: Characteristics and performance, Earth Planet. Sci. Lett., 294, 506-519, doi:10.1016/j.epsl.2009.11.007.

Hartmann, W., and G. Neukum (2001), Cratering chronology and the evolution of Mars, Space Sci. Rev., 96, 165-194.

Hauber, E., et al. (2006), Geomorphological and mineralogical mapping of Hebes Chasma, Mars, paper presented at European Planetary Science Congress 2006, p. 332, Berlin.

Hayward, R., K. Mullins, L. Fenton, T. Hare, T. Titus, M. Bourke, A. Colaprete, and P. Christensen (2007a), Mars Global Digital Dune Database: MC2-MC29, U.S. Geol. Surv. Open File Rep., 2007-1158.

Hayward, R. K., K. F. Mullins, L. K. Fenton, T. M. Hare, T. N. Titus, M. C. Bourke, A. Colaprete, and P. R. Christensen (2007b), Mars Global Digital Dune Database and initial science results, J. Geophys. Res., 112, E11007, doi:10.1029/2007JE002943.

Head, J., et al. (2001), Geological processes and evolution, Space Sci. Rev., 96, 263-292.

Hoefen, T., R. Clark, J. Bandfield, M. Smith, J. Pearl, and P. Christensen (2003), Discovery of olivine in the Nili Fossae region of Mars, Science, 302, 627-630, doi:10.1126/science. 1089647 .

Hoke, M. R. T., and B. M. Hynek (2009a), Valley network formation on the ancient highlands of Mars occurred in the late Noachian and early Hesperian epochs, Lunar Planet. Sci., XL, Abstract 1885.

Hoke, M. T., and B. Hynek (2009b), Roaming zones of precipitation on ancient Mars as recorded in valley networks, J. Geophys. Res., 114, E08002, doi:10.1029/2008JE003247.

Hynek, B. M., and R. J. Phillips (2001a), The enigmantic Arabia Terra, Mars, in Field Trip and Workshop on the Martian Highlands and Mojave Desert Analogs, edited by A. D. Howard, LPI Contrib., 1101 , Abstract 4017

Hynek, B. M., and R. J. Phillips (2001b), The role of water in the evolution of the enigmatic Arabia Terra, Mars, Eos Trans. AGU, 82(47) Fall Meet. Suppl., Abstract P22A-0538.
Hynek, B., R. Arvidson, and R. Phillips (2002), Geologic setting and origin of Terra Meridiani hematite deposit on Mars, J. Geophys. Res., 107(E10), 5088, doi:10.1029/2002JE001891.

Iversen, J., and B. White (1982), Saltation thresholds on Earth, Mars, and Venus, Sedimentology, 29, 111-119.

Jacobshagen, V., J. Arndt, H.-J. Goetze, D. Mertmann, and C. Wallfass (2000), Einfuehrung in die Geologischen Wissenschaften, Eugen Ulmer, Stuttgart, Germany.

Jaumann, R. (2003), Die Erosionsmorphologie des Mars: Genese, Verteilung und Stratigraphie von Erosionsformen und deren klimatische Bedeutung, DLR Forschungsbericht 2003-20, habilitation dissertation, LudwigMaximilians Univ., Munich, Germany.

Jaumann, R., et al. (2006), Dark materials in Martian craters, Lunar Planet. Sci., XXXVII, Abstract 1735 .

Jaumann, R., et al. (2007), The high-resolution stereo camera (HRSC) experiment on Mars Express: Instrument aspects and experiment conduct from interplanetary cruise through the nominal mission, Planet. Space Sci., 55, 928-952.

Jaumann, R., A. Nass, D. Tirsch, D. Reiss, and G. Neukum (2009), The western Libya Montes valley system on Mars: Evidence for episodic and multi-genetic erosion events during the Martian history, Earth Planet. Sci. Lett., 294, 272-290.

Jouglet, D., F. Poulet, R. E. Milliken, J. F. Mustard, J. P. Bibring, Y. Langevin, B. Gondet, and C. Gomez (2007), Hydration state of the Martian surface as seen by Mars Express OMEGA: 1. Analysis of the $3 \mu \mathrm{m}$ hydration feature, J. Geophys. Res., 112, E08S06, doi:10.1029/ 2006JE002846.

Komar, P. D. (1980), Modes of sediment transport in channelized water flows with ramifications to the erosion of the Martian outflow channels, Icarus, 42, 317-329, doi:10.1016/0019-1035(80)90097-4.

Lanz, J. (2004), Geometrische, morphologische und stratigraphische Untersuchungen ausgewählter Outflow Channel der Circum-Chryse-Region, Mars, mit Methoden der Fernerkundung, DLR Forschungsbericht 2004-02, Ph.D. dissertation, Freie Univ., Berlin.

Loizeau, D., et al. (2007a), Stratigraphic correlation between the clays of the region of Mawrth Vallis as detected by OMEGA, and HRSC color images and DTM, in Seventh International Conference on Mars, July 9-13, 2007, Pasadena CA [CD-ROM], LPI Contrib., 1353, Abstract 3131.

Loizeau, D., et al. (2007b), Phyllosilicates in the Mawrth Vallis region of Mars, J. Geophys. Res., 112, E08S08, doi:10.1029/2006JE002877.

Loizeau, D., et al. (2008), Stratigraphy of the Mawrth Vallis region through omega, HRSC color imagery and DTM, Lunar Planet. Sci., XXXIX, Abstract 1586.

Lucey, P., and R. Clark (1984), Spectral properties of water ice and contaminants, in Ices in the Solar System, edited by J. Klinger et al., pp. 155-168, Reidel, Dordrecht, Netherlands.

Malin, M., and K. Edgett (2001), Mars Global Surveyor Mars Orbiter Camera: Interplanetary cruise through primary mission, J. Geophys Res., 106, 23,429-23,570.

Malin, M. C., G. E. Danielson, A. P. Ingersoll, H. Masursky, J. Veverka, M. A. Ravine, and T. A. Soulanille (1992), Mars observer camera, J. Geophys. Res., 97, 7699-7718.

Mangold, N., et al. (2007), Mineralogy of the Nili Fossae region with OMEGA/Mars Express data: 2. Aqueous alteration of the crust, J. Geophys. Res., 112, E08S04, doi:10.1029/2006JE002835.

Mangold, N., D. Loizeau, A. Gaudin, V. Ansan, J. Michalski, F. Poulet, and J. P. Bibring (2010a), Connecting fluvial landforms and the stratigraphy of Mawrth Vallis phyllosilicates: Implications for chronology and alteration processes, LPI Contrib., 1547, Abstract 6010

Mangold, N., D. Baratoux, O. Arnalds, J. M. Bardintzeff, B. Platvoët, M. Grégoire, and P. Pinet (2010b), Segregation of olivine grains in volcanic sands in Iceland: Implications for Mars, LPI Contrib., 1552, 47-48.

Marchenko, A. G., A. T. Basilevsky, H. Hoffmann, E. Hauber, A. C. Cook, and G. Neukum (1998), Geology of the common mouth of the Ares and Tiu Valles, Mars, Solar Syst. Res., 32, 425-452.

Markl, G. (2004), Minerale und Gesteine: Eigenschaften, Bildung, Untersuchung, Spektrum, Munich, Germany.

Masursky, H., J. Boyce, A. Dial, G. Schaber, and M. Strobell (1977), Classification and time of formation of Martian channels based on Viking data, J. Geophys. Res., 82, 4016-4038.

Matthes, M. (2001), Mineralogie: Eine Einfuehrung in die spezielle Mineralogie, Petrologie und Lagerstaettenkunde, Springer, Berlin.

McCauley, J., M. Carr, J. Cutts, W. Hartmann, H. Masursky, D. Milton, R. Sharp, and D. Wilhelms (1972), Preliminary Mariner 9 report on the geology of Mars, Icarus, 17, 289-327.

McCord, T., and R. Clark (1978), Mars: Near-infrared spectra reflectance and compositional implications, J. Geophys. Res., 83, 5433-5441. 
McEwen, A., et al. (2007), Mars Reconnaissance Orbiter's High Resolution Imaging Science Experiment (HiRISE), J. Geophys. Res., 112, E05S02, doi:10.1029/2005JE002605

Michalski, J. R., E. Z. Noe Dobrea, R. Fergason, and M. Golombek (2007), Geologic mapping of the Mawrth Vallis region, Mars: Clues to the origin of clay mineral deposits, Lunar Planet. Sci., XXXVIII, Abstract 1065.

Mullins, K., R. Hayward, T. Titus, M. Bourke, and L. Fenton (2005), Mars Digital Dune Database: A quantitative look at the geographic distribution of dunes on Mars, Lunar Planet. Sci., XXXVI, Abstract 1986.

Murchie, S., et al. (2004), CRISM (Compact Reconnaissance Imaging Spectrometer for Mars) on MRO (Mars Reconnaissance Orbiter), Proc. SPIE, 5660, 66-77, doi:10.1117/12.578976.

Mustard, J. F. (2002), A wet and altered Mars, Nature, 417, 234-235.

Mustard, J. F., F. Poulet, A. Gendrin, J. P. Bibring, Y. Langevin, B. Gondet, N. Mangold, G. Bellucci, and F. Altieri (2005), Olivine and pyroxene diversity in the crust of Mars, Science, 307, 1594-1597, doi:10.1126/science.1109098.

Mustard, J. F., F. Poulet, J. Head, N. Mangold, J.-P. Bibring, S. Pelkey, C. Fassett, Y. Langevin, and G. Neukum (2007), Mineralogy of the Nili Fossae region with OMEGA/Mars Express data: 1. Ancien impact melt in the Isidis Basin and implications for the transition from the Noachian to Hesperian, J. Geophys. Res., 112, E08S03, doi:10.1029/ 2006JE002834.

Nedell, S. S., S. W. Squyres, and D. W. Andersen (1987), Origin and evolution of the layered deposits in the Valles Marineris, Mars, Icarus, 70, 409-441, doi:10.1016/0019-1035(87)90086-8.

Nelson, D., and R. Greeley (1999), Geology of Xanthe Terra outflow channels and the Mars Pathfinder landing site, J. Geophys. Res., 104, 8653-8670, doi:10.1029/98JE01900.

Neukum, G., and K. Hiller (1981), Martian ages, J. Geophys. Res., 86, 3097-3121.

Neukum, G., R. Jaumann, the HRSC Co-Investigator and Experiment Team (2004a), HRSC: The High Resolution Stereo Camera of Mars Express, Eur. Space Agency Spec. Publ., ESA SP-1240, 1-19.

Neukum, G., et al. (2004b), Recent and episodic volcanic and glacial activity on Mars revealed by the High Resolution Stereo Camera, Nature, 432 971-979.

Pelkey, S. M., et al. (2007), CRISM multispectral summary products: Parameterizing mineral diversity on Mars from reflectance, J. Geophys. Res., 112, E08S14, doi:10.1029/2006JE002831.

Pieters, C. (1977), Characterization and distribution of lunar mare basalt types using remote sensing techniques, Ph.D. dissertation, Mass. Inst. of Technol., Cambridge.

Poulet, F., and S. Erard (2004), Nonlinear spectral mixing: Quantitative analysis of laboratory mineral mixtures, J. Geophys. Res., 109, E02009, doi:10.1029/2003JE002179.

Poulet, F., J. P. Bibring, J. F. Mustard, A. Gendrin, N. Mangold, Y. Langevin, R. E. Arvidson, B. Gondet, and C. Gomez (2005), Phyllosilicates on Mars and implications for early Martian climate, Nature, 438, 623-627, doi:10.1038/nature04274.

Poulet, F., C. Gomez, J. P. Bibring, Y. Langevin, B. Gondet, P. Pinet, G. Belluci, and J. Mustard (2007), Martian surface mineralogy from Observatoire pour la Minéralogie, l'Eau, les Glaces et l'Activité on board the Mars Express spacecraft (OMEGA/MEX): Global mineral maps, J. Geophys. Res., 112, E08S02, doi:10.1029/2006JE002840.

Poulet, F., R. Arvidson, C. Gomez, R. Morris, J.-P. Bibring, Y. Langevin, B. Gondet, and J. Griffes (2008), Mineralogy of Terra Meridiani and western Arabia Terra from OMEGA/MEX and implications for their formation, Icarus, 195, 106-130.

Poulet, F., et al. (2009a), Quantitative compositional analysis of Martian mafic regions using the MEX/OMEGA reflectance data: 2. Petrological implications, Icarus, 201, 84-101, doi:10.1016/j.icarus.2008.12.042.

Poulet, F., et al. (2009b), Quantitative compositional analysis of Martian mafic regions using the MEx/OMEGA reflectance data: 1 . Methodology, uncertainties and examples of application, Icarus, 201, 69-83, doi:10.1016/j.icarus.2008.12.025.

Roach, L. H., et al. (2007), Sulfate identification in East Candor, Valles Marineris with CRISM visible-infrared spectra, Lunar Planet. Sci., XXXVIII, Abstract 2106.

Rogers, D., and P. Christensen (2003), Age relationship of basaltic and andesitic surface compositions on Mars: Analysis of high-resolution TES observations of the northern hemisphere, J. Geophys. Res., 108(E4), 5030, doi:10.1029/2002JE001913.

Ruff, S. W., and P. Christensen (2002), Bright and dark regions on Mars: Particle size and mineralogical characteristics based on Thermal Emission Spectrometer data, J. Geophys. Res., 107(E12), 5127, doi:10.1029/ 2001JE001580.

Sagan, C., et al. (1972), Variable features on Mars: Preliminary Mariner 9 television results, Icarus, 17, 346-372.
Schatz, V., H. Tsoar, K. Edgett, and E. Parteli (2006), Evidence for indurated sand dunes in the Martian north polar region, J. Geophys. Res., 111, E04006, doi:10.1029/2005JE002514.

Scholten, F., et al. (2005), Mars Express HRSC data processing: Methods and operational aspects, Photogramm. Eng. Remote Sens., 71(10), 1143-1152.

Schultz, P., and J. Mustard (2004), Impact melts and glasses on Mars, J. Geophys. Res., 109, E01001, doi:10.1029/2002JE002025.

Scott, D., and K. Tanaka (1986), Geology map of the western equatorial region of Mars, U.S. Geol. Surv. Misc. Invest. Map, I-1802-A, $1: 15,000,000$.

Shkuratov, Y., L. Starukhina, H. Hoffmann, and G. Arnold (1999), A model of spectral albedo of particulate surfaces: Implications for optical properties of the moon, Icarus, 137, 235-246.

Silverglate, P. R., and D. E. Fort (2004), System design of the CRISM (Compact Reconnaissance Imaging Spectrometer for Mars) hyperspectral imager, Proc. SPIE, 5159, 283-290, doi:10.1117/12.504876.

Silverglate, P., et al. (2004), Compact Reconnaissance Imaging Spectrometer for Mars (CRISM): Characterization results for instrument and focal plane subsystems, Proc. SPIE, 5563, 98-110, doi:10.1117/12.559882.

Silvestro, S., L. K. Fenton, and D. A. Vaz (2010), Ripple migration and small modifications of active dark dunes in Nili Patera (Mars), Lunar Planet. Sci., XLI, Abstract 1820.

Singer, R. B. (1980a), The dark materials on Mars: I. new information from reflectance spectroscopy on the extent and mode of oxidation, Proc. Lunar Planet. Sci. Conf., 11th, 1045-1047.

Singer, R. B. (1980b), The composition of the Martian dark regions: Observations and analysis, Ph.D. dissertation, Univ. of Hawaii, Honolulu.

Singer, R. B., and T. B. McCord (1979), Mars: Large-scale mixing of bright and dark materials and properties of dark material, Proc. Lunar Planet. Sci. Conf., 10th, 1128-1130.

Singer, R. B., and T. L. Roush (1983), Spectral reflectance properties of particulate weathered coatings on rocks: Laboratory modeling and applicability to Mars, Proc. Lunar Planet. Sci. Conf., 14th, 708-709.

Sowe, M., E. Hauber, R. Jaumann, K. Gwinner, F. Fueten, R. Stesky, and G. Neukum (2007), Interior layered deposits in the eastern Valles Marineris and Chaotic Terrains on Mars, Lunar Planet. Sci., XXXVIII, Abstract 1568.

Stoeffler, D., G. Ryder, B. Ivanov, N. Artemieva, M. Cintala, and R. Grieve (2006), Cratering history and lunar chronology, in New Views of the Moon, edited by B. Jolliff et al., pp. 519-588, Mineral. Soc. of Am., Chantilly, Va.

Tanaka, K., D. Scott, and R. Greeley (1992), Global stratigraphy, in Mars, edited by H. Kiefer et al., pp. 345-382, Univ. of Ariz. Press, Tucson.

Tanaka, K., J. Rodriguezb, J. Skinner Jr., M. Bourke, C. Fortezzo, K. Herkenhoff, E. Kolb, and C. Okubo (2008), North polar region of Mars: Advances in stratigraphy, structure, and erosional modification, Icarus, 196, 318-358.

Thomas, P. (1984), Martian intracrater spotches: Occurrence, morphology, and colors, Icarus, 57, 205-227.

Thomas, P., J. Veverka, S. Lee, and A. Bloom (1981), Classification of wind streaks on Mars, Icarus, 45, 124-153.

Tirsch, D. (2009), Dark dunes on Mars: Analyses on origin, morphology and mineralogical composition of the dark material in Martian craters, Ph.D. dissertation, Freie Univ., Berlin.

Tirsch, D., R. Jaumann, D. Reiss, J. Helbert, F. Forget, E. Millour, F. Poulet, and G. Neukum (2007), Dark dunes in Martian craters, Lunar Planet. Sci., XXXVIII, Abstract 1569.

Tirsch, D., R. Jaumann, A. Pacifici, F. Poulet, L. H. Roach, J. F. Mustard, J. P. Bibring, and G. Neukum (2009), Dark layers as local sources for the dark intra-crater dunes on Mars, Lunar Planet. Sci., XL, Abstract 1004

Werner, S. (2006), Major aspects of the chronostratigraphy and geologic evolutionary history of Mars, Ph.D. dissertation, Freie Univ., Berlin.

Wrobel, K. E., and P. H. Schultz (2004), Effect of planetary rotation on distal tektite deposition on Mars, J. Geophys. Res., 109, E05005, doi:10.1029/2004JE002250

Wrobel, K. E., and P. H. Schultz (2006), The generation and distribution of Martian impact melt/glass: A computational study with implications for the nature of dark surface materials, Lunar Planet. Sci., XXXVII, Abstract 2386.

Wrobel, K. E., and P. H. Schultz (2007), The significant contribution of impact glass to the Martian surface record, in Seventh International Conference on Mars, July 9-13, 2007, Pasadena CA [CD-ROM], LPI Contrib., 1353, Abstract 3093.

Wyatt, M. B., and H. McSween Jr. (2002), Spectral evidence for weathered basalt as an alternative to andesite in the northern lowlands of Mars, Nature, 417, 263-266. 
Wyatt, M., V. Hamilton, H. McSween Jr., P. Christensen, and L. Taylor (2001), Analysis of terrestrial and Martian volcanic compositions using thermal emission spectroscopy: 1. Determination of mineralogy, chemistry and classification strategies, J. Geophys. Res., 106, 14,711-14,732.

Zimbelman, J. (2000), Non-active dunes in the Acheron Fossae region of Mars between the Viking and Mars Global Surveyor eras, Geophys. Res. Lett., 27(7), 1069-1072.

Zuber, M., D. Smith, R. Phillips, S. Solomon, W. Banerdt, G. Neumann, and O. Aharonson (1998), Shape of the northern hemisphere of Mars from the Mars Orbiter Laser Altimeter (MOLA), Geophys. Res. Lett., 25(24), 4393-4396.

R. Jaumann and D. Tirsch, Institute of Planetary Research, German Aerospace Center, Rutherfordstr. 2, D-12489 Berlin, Germany. (daniela. tirsch@dlr.de)

A. Pacifici, IRSPS, Universita d'Annunzio, Viale Pindaro 42, I-65127 Pescara, Italy.

F. Poulet, Institut d'Astrophysique Spatiale, Université Paris-Sud, Bât. 121, F-91405 Orsay CEDEX, France. 